\title{
A Rationale for Pollutograph Evaluation in Ungauged Areas, Using Daily Rainfall Patterns: Case Studies of the Apulian Region in Southern Italy
}

\author{
Angela Gorgoglione, ${ }^{1,2}$ Andrea Gioia, ${ }^{1}$ Vito Iacobellis, ${ }^{1}$ \\ Alberto Ferruccio Piccinni, ${ }^{1}$ and Ezio Ranieri ${ }^{1}$ \\ ${ }^{1}$ DICATECh, Politecnico di Bari, Via Orabona 4, 70125 Bari, Italy \\ ${ }^{2}$ Department of Civil and Environmental Engineering, University of California, Davis, One Shields Avenue, Davis, \\ CA 95616, USA \\ Correspondence should be addressed to Angela Gorgoglione; angela.gorgoglione@poliba.it
}

Received 27 November 2015; Accepted 4 January 2016

Academic Editor: Artemi Cerda

Copyright @ 2016 Angela Gorgoglione et al. This is an open access article distributed under the Creative Commons Attribution License, which permits unrestricted use, distribution, and reproduction in any medium, provided the original work is properly cited.

In the context of the implementation of sustainable water treatment technologies for soil pollution prevention, a methodology that try to overcome the lack of runoff quality data in Puglia (Southern Italy) is firstly tackled in this paper. It provides a tool to obtain total suspended solid (TSS) pollutographs in areas without availability of monitoring campaigns. The proposed procedure is based on the relationship between rainfall characteristics and pollutant wash-off. In particular, starting from the evaluation of the observed regional rainfall patterns by using a rainfall generator model, the storm water management model (SWMM) was applied on five case studies located in different climatic subareas. The quantity SWMM parameters were evaluated starting from the drainage network and catchments characteristics, while the quality parameters were obtained from results of a monitoring campaign conducted for quality model calibration and validation with reference to the pollutograph's shape and the peak-time. The research yields a procedure useful to evaluate the first flush phenomenon in ungauged sites and, in particular, it provides interesting information for designing efficient and sustainable drainage systems for first flush treatment and diffuse pollution treatment.

\section{Introduction}

The concentration of human population near cities has increased markedly in recent years all over the world. The improvements in transportation, the expansion of manufacturing industries, and increased employment opportunities have resulted in increased density of population in cities. Due to this process, known as urbanization, the natural characteristics of the land are changed by various anthropogenic activities common to urban areas. These anthropogenic activities are among the most important pollutant sources [1]. Thus, numerous pollutants are introduced into the urban environment by vehicular traffic, industrial processes, building construction, and commercial activities, which are carried by stormwater. It is not surprising that the characterization of quality of stormwater that washes away impervious surfaces is assuming growing importance in the last few years [2-4]. The impact of the mentioned above activities on the water environment includes increased risks in terms of floods, erosion and degradation of stream habitats, and deterioration of water quality $[5,6]$.

Moreover it is worth mentioning that there is a very strong correlation between stormwater quality and soil contamination for both anthropized and natural areas. In natural areas a significant fraction of precipitation infiltrates into the soil, usually covered by forest, woods, or grass. This water infiltrates as it travels underground, allowing the increasing of soil contamination and the alteration of the natural porosity of the soil. In the anthropized area, stormwater runoff increases in both rate and volume due to increases of impervious area and soil compaction; this development dramatically alters the hydrologic cycle by changing 
the relative percentage of precipitation that contributes to groundwater recharge, evapotranspiration, and runoff by adding impervious surfaces.

Starting from the seventies, several studies, based on monitoring campaigns, have been carried out in order to evaluate the characterization of the quality of stormwater runoff of urbanized areas and to analyze the buildup/washoff and transport phenomena of pollutants during wet periods in both separate and combined sewer systems [715]. Nowadays, the quality data collected during monitoring campaigns represent an important dataset; nevertheless the featured Apulian urban landscapes, characterized by peculiar socioeconomic, climatic, and geological conditions, require further experimental assessments [16].

Measurements and monitoring campaigns are useful to provide important information necessary to define models and to enhance design procedures for improving the efficiency of systems for water treatment. In this context, it is necessary to ensure high cooperation between measurements and modeling, which significantly affects an overall success of the whole work. Regarding the equipment used for the monitoring campaign, it is important to select measurement devices with a high degree of reliability and also to put emphasis on the interfacing of the adopted equipment (according to the operation and maintenance). Moreover, in order to be able to handle such amount of data, it is necessary to have relevant and capable software tools for data processing. Finally, it is necessary to mention that the efficiency and success of the monitoring activities depend on the planning and the organization of each measurement campaign. On the base of these considerations, monitoring campaigns are very expensive and conspicuous; therefore, a functional database of runoff quality is quite difficult to collect, especially in areas where the monitoring network is characterized by lack of discharge gauged stations and low frequency of precipitation.

In the context of stormwater treatment design, another important topic highlighted in recent literature is the need of deeper understanding of the relationship between pollutant wash-off processes and rainfall characteristics [17, 18]. Past research studies commonly consider rainfall characteristics included in lumped parameters in numerical models used for investigating the role of rainfall characteristics on pollutant wash-off [17, 19-21].

Based on these considerations, in this paper, a methodology that try to overcome the lack of runoff quality data in Puglia (Southern Italy) is tackled. It provides a tailored relationship between rainfall characteristics and pollutant washoff in the context of the implementation of water treatment procedures for preventing the soil pollution. In particular, we exploited the iterated random pulse (IRP) rainfall generator model proposed by Veneziano and Iacobellis [22], by finding climatic subareas, characterized by different rainfall features. Time series of precipitation generated by the IRP model were used as input data in the quality model, providing information about qualitative characteristics of runoff in urban catchments. The above-mentioned model takes into account also the influence of catchment characteristics such as surface area, land use, percentage of impervious surface, and slope on pollutant wash-off process. For example, the impervious surface area layout plays an important role in runoff routing, controlling the time of concentration and hence influencing the pollutant wash-off process [23].

In the previous work, Di Modugno et al. [24], a monitoring campaign was carried out within a residential area by collecting and evaluating quantity and quality data. With reference to the buildup/wash-off processes, total suspended solid (TSS) concentrations were used for calibration of storm water management model (SWMM), which was validated on the base of the pollutograph's shape and the peak-time for a urban basin located in Sannicandro di Bari (central Puglia, Italy). The quality parameters identified were used in the present work for evaluating the pollutant wash-off processes in five urban basins of the region, located in Barletta, Manduria, Cagnano Varano, Presicce, and Ginosa Marina, using synthetic rainfall series generated by IRP model with parameters accounting for regional rainfall patterns $[25,26]$.

Since past researches were focused above all on rural areas [27-35] and less effort has been done about anthropized areas [36], the present work provides an important contribution to this topic, by improving the stormwater treatment design (i.e., first flush capturing devices) in the context of soil pollution prevention in Mediterranean semiarid areas. Moreover it provides a deeper understanding of stormwater quality modeling approaches where commonly, the pollutant wash-off process is reproduced using only the rainfall intensity rather than other rainfall event parameters or using a stochastic approach without considering the characteristics of the rainfall event.

In phase $\mathrm{A}$, reported in Section 2, the SWMM model is briefly described, distinguishing between the calibrated parameters in previous work [24] and those evaluated by considering catchment characteristics. In phase B, reported in Section 3, the rainfall generator model providing the synthetic time series of precipitation (used as input in SWMM model) is described. Moreover, in the same section, the regional pattern of rainfall features is explained. In phase C, as reported in Section 4, the catchment characteristics of Barletta, Manduria, Cagnano Varano, Presicce, and Ginosa Marina municipalities are described and in Section 5 the pollutographs evaluated coupling the IRP and the SWMM models are shown and discussed. The conclusions are presented in Section 6.

\section{Phase A: Estimation of SWMM Model Parameters}

The main objective of the research presented is to improve the stormwater quality evaluation in areas ungauged. With this aim, the quality model parameters calibrated by $\mathrm{Di}$ Modugno et al. [24] for the case study of Sannicandro di Bari, where a monitoring campaign is available, are exported to the catchments located in Barletta, Manduria, Cagnano Varano, Presicce, and Ginosa Marina municipalities (described in phase C). In this way, for each rainfall station, time series of precipitation of suitable length may be generated in order to be implemented in SWMM model to evaluate the subsequent pollutographs. 
2.1. The Storm Water Management Model (SWMM). SWMM simulates the hydrograph and the pollutograph [37] for a real storm event (for single and long-term event) on the base of rainfall (hyetograph) and other meteorological inputs and system characteristics (catchment, conveyance, and storage/treatment) for developed urban and undeveloped or rural areas. The runoff component of SWMM operates on a collection of subcatchment areas that receive precipitation and generate runoff and pollutant loads. The routing portion of SWMM transports this runoff overland and underground through a system of pipes, channels, storage and treatment devices, pumps, and regulators. SWMM tracks the quantity and quality of runoff generated within each subcatchment and the flow rate, flow depth, and quality of water in each pipe and channel during a simulation period characterized by multiple time steps [38].

The losses taken into account in the present work are represented by the infiltration process that was modeled evaluating, for each subcatchment, the percentage of pervious and impervious area obtained from the land use map. The infiltration model used in this study is based on Horton's equation, whose parameters values have been chosen according to the typical values reported in literature [39, 40], in relation to soil type, and specifically tested in the Apulian karstic watersheds [41].

SWMM allows evaluating the pollutants buildup process on the basin surface, all processes involving the solid transportation by runoff through the drainage system.

Pollutant buildup within a land use category is described by a mass per unit of subcatchment area; the amount of buildup is a function of the number of dry weather days antecedent to the rainfall event. On the base of the assumptions of Alley and Smith [42], the buildup function follows an exponential growth curve that approaches a maximum limit asymptotically as in

$$
M_{a}\left(d_{t s}\right)=\left(\frac{\mathrm{Accu}}{\mathrm{Disp}}\right) \cdot A \cdot P_{\mathrm{imp}} \cdot\left(1-e^{-\left(\mathrm{Disp} \cdot d_{t s}\right)}\right),
$$

where $M_{a}\left(d_{t s}\right)$ is the pollutant buildup during the antecedent dry days [ $\mathrm{kg} / \mathrm{ha}$ ]; Disp identifies the disappearance of accumulated solids due to the action of wind or vehicular traffic $[1 / \mathrm{d}] ; A \cdot P_{\text {imp }}$ represents the impervious area percentage; Accu characterizes the solids buildup rate $[\mathrm{kg} /(\mathrm{ha} \cdot \mathrm{d})]$; (Accu/Disp) $\cdot A \cdot P_{\text {imp }}$ represents the maximum asymptotical limit of the buildup curve.

The pollutant wash-off over different land uses takes place during wet periods and it was described by the Jewell and Adrian [43] exponential function:

$$
\frac{d M_{d}(t)}{d t}=- \text { Arra } \cdot i(t)^{\text {wash }} \cdot M_{a}(t),
$$

where $d M_{d}(t) / d t$ represents the wash-off load in units of mass per hour; Arra is the wash-off coefficient $\left[\mathrm{mm}^{-1}\right] ; i(t)$ is the runoff rate; wash is the wash-off exponent, a numerical parameter that controls the influence of rainfall intensity on the amount of leached pollutants.
2.2. Estimation of Quantity and Quality Parameters. Several works [44-49] report sensitivity analysis performed to assess the importance of various parameters in SWMM equations that most affect results in terms of runoff and water quality.

In particular, Liong et al. [45] subdivided the calibration parameters of the Runoff block of SWMM into two groups:

(1) First group is "Traditional" calibration parameters, which include Manning's coefficient for overland flow over the pervious and impervious portion of the subcatchment (N-Perv and N-Imperv), the depth of depression storage on the pervious and impervious portion of the Subcatchment (Dstore-Perv and Dstore-Imperv), and the infiltration parameters.

(2) Second group is "Nontraditional" calibration parameters, whose values are obtained from the measures and/or the interpretation of the available information. Sources of information, which provide the definition of a specific value associated with the parameter, are, for instance, topographic maps, aerial photographs, and land use maps. Since topographic maps may be plotted at different scales, larger errors can be expected for the subcatchment areas represented by a larger map scale; these areas are in turn used to compute the widths of the overland flow path; errors are also inevitable in assigning values to slopes, from the topographical map. Similarly, errors can be expected in the values assigned to the fraction of imperviousness (\% Imperv), the percentage of impervious area with no depression storage (\% Zero Imperv), and the roughness coefficients for the channel (Roughness).

In the present work, as well as in [24], values extracted from the literature $[41,50,51]$ were assigned to all parameters belonging to the first group. The infiltration losses parameters were estimated, in relation to soil type, by using values tabulated in technical handbooks and verified by [40] for karstic areas. The range of variation and the values chosen for these parameters are shown in Table 1.

In Table 1, among "Traditional" calibration parameters, the percentage of impervious area with no depression storage (\% Zero Imperv) was added, because there is not enough information available to evaluate it for the investigated basins. Therefore, as for as Sannicandro di Bari, a mean-low value of $\%$ Zero Imperv was chosen, corresponding to a quite high runoff generation potential such that it is expected in an urban basin.

Regarding the other "Nontraditional" calibration parameters, area, width, slope, percentage of impervious area, and roughness coefficients for the channel, they were evaluated for the five case studies investigated and are reported in Table 5.

All the parameters mentioned above are referred to the hydraulic-hydrological model. Since the main objective of the proposed research is to extend the stormwater quality evaluation to ungauged areas, in this work the same quality parameter values obtained from the calibration and validation procedure (based on monitoring campaign) in Sannicandro di Bari [24] were considered and they are listed in Table 2. 
TABLE 1: "Traditional” calibration parameters of the hydraulic-hydrological model.

\begin{tabular}{|c|c|c|c|}
\hline Parameters & Description & Range & Value \\
\hline Dstore-Imperv & Depth of depression storage on the impervious portion of the subcatchment [mm] & $1.27-2.54^{*}$ & 1.30 \\
\hline Dstore-Perv & Depth of depression storage on the pervious portion of the subcatchment [mm] & $2.54-5.08^{*}$ & 2.60 \\
\hline N-Imperv & $\begin{array}{l}\text { Manning's coefficient for overland flow over the impervious portion of the } \\
\text { subcatchment }\end{array}$ & $0.011-0.024^{* *}$ & 0.012 \\
\hline N-Perv & $\begin{array}{l}\text { Manning's coefficient for overland flow over the previous portion of the } \\
\text { subcatchment }\end{array}$ & $0.15-0.41^{* *}$ & 0.15 \\
\hline \%Zero Imperv & Percent of the impervious area with no depression storage [\%] & - & 45 \\
\hline \multirow{3}{*}{ Horton's equation } & Maximum infiltration rate $[\mathrm{mm} / \mathrm{h}]$ & $117-76^{* * *}$ & 76 \\
\hline & Minimum infiltration rate $[\mathrm{mm} / \mathrm{h}]$ & $17-6^{* * *}$ & 13 \\
\hline & Decay constant $[1 / \mathrm{h}]$ & $5.34-4.14^{* * *}$ & 4.14 \\
\hline
\end{tabular}

${ }^{*}$ Reference [50]; ${ }^{* *}$ reference [51]; ${ }^{* * *}$ reference [41].

TABLE 2: Calibrated quality parameters exported in ungauged basins.

\begin{tabular}{lcc}
\hline Parameters & Range & Value \\
\hline Buildup & & \\
$\quad$ Accu [kg/(ha·d)] & $10-25^{*}$ & 13.143 \\
Disp [1/d] & $0.08^{* *}$ & 0.08 \\
Wash-off & & \\
Arra [1/mm] & $0.11-0.19$ & 0.18 \\
Wash & $0-3$ & 2.35 \\
\hline
\end{tabular}

${ }^{*}$ For highly populated residential areas.

** Italian residential basin typical values.

\section{Phase B: Identification of Climatic Subareas}

In this paper we subdivided the entire Puglia region in different climatic subareas, consistently with the parametrization of the IRP rainfall generator model proposed by Veneziano and Iacobellis [22]. Then, time series of precipitation generated by the IRP model were used as input data of the quality model, providing qualitative characteristics of runoff in urban catchments. These results provide interesting information useful to enhance treatment procedures and to improve the efficiency of systems aimed at first flush treatment. In the following subsections, the structure of the IRP model and the approach for identification of different rainfall features are briefly described.

3.1. IRP Model. The rainfall generator proposed by Veneziano and Iacobellis [22] uses the classical representation of the exterior process of the rainfall as an alternating process with independent mean rainfall intensities for different rainstorms, characterizing the duration and average intensity of rainfall events at the synoptic scale. The interior process exploits the IRP, Veneziano et al. [52], pulse representation with multifractal properties of location and intensity, describing the detailed fluctuations of rainfall intensity at subsynoptic scales. In particular the wet periods of the exterior model are scattered through the "interior" scheme, in which rainfall is represented as the superposition of pulses with a hierarchically nested structure of temporal occurrences; pulses at different scales have amplitudes with cascade-like dependence.

The exterior process consists of an alternating sequence of dry and wet periods with independent durations, which characterizes the arrival, duration, and average intensity of rainfall events at the synoptic scale; the distribution of the wet periods is assumed to be exponentially distributed instead of that of the dry periods which is assumed to be Weibull distributed; the average rainfall intensities in different wet periods are independent and identically distributed as exponential distribution.

The model consists of six parameters derived from the study of the precipitation process aggregate in the exterior and interior processes mentioned above. The exterior process is characterized by four parameters: the mean duration of the wet periods $\left(m_{\tau \text { wet }}\right)$, the mean value $\left(m_{\tau \text { dry }}\right)$, and the exponent $k$ of the Weibull distribution of the dry intervals and the mean value $\left(m_{I}\right)$ of the average of rainfall intensity during the synoptic events, while for the definition of the interior process two other parameters related to its multifractality are introduced: the parameter $C_{1}$ that controls the multifractal properties of rainfall at small scales and the multiplicity $r$ which controls the quasifractal behavior of the rainfall support at small scales; the latter assumes a value equal to 2 .

3.2. Different Rainfall Patterns in Puglia. Iacobellis et al. [53] evaluated the parameters of the IRP rainfall generator for all the rainfall time series of the monitoring network of the Regional Hydrographic Service reported in the Hydrological Annals. For this purpose they used the method of estimation from coarse data proposed by Iacobellis et al. [54], the daily rainfall records, and the annual maxima hourly precipitation intensities for 124 different sites of Puglia, Basilicata, and Campania in Southern Italy located in the following river basins: Candelaro, Cervaro, Carapelle, Ofanto, Lesina and Varano Lakes, Gargano, Salso-Salpi Lakes, Celentano marshes, Murge, Salento, Lato, and Galeso.

The significant rain gauges considered for this study were those with daily rainfall time series not shorter than twenty years. Moreover, all the values characterized by a particular uncertainty (i.e., the data obtained by interpolation and those accumulated over a given period) have been deleted from 


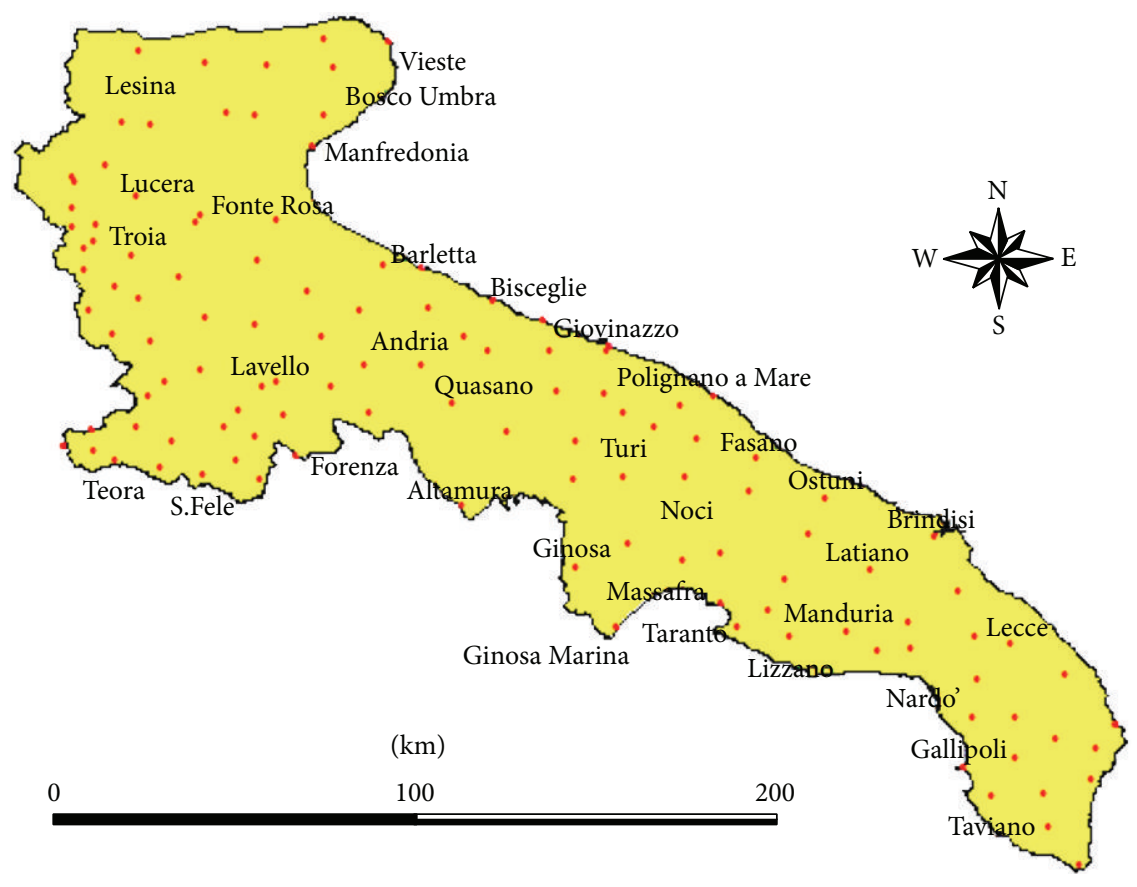

Figure 1: Rain gauges stations located in Puglia.

the time series reported in the Hydrological Annals. Figure 1 shows the position of the gauged rainfall stations considered.

The values of daily precipitation, organized as a vector, were processed in Matlab environment, in order to evaluate the four parameters of the exterior model. Starting from this vector, the following processes were studied:

(i) The distribution of wet periods called "wet distribution": assuming that the variable "consecutive number of rainy days" $\left(\tau_{\text {wet }}\right)$ or "duration of a storm" is characterized by an exponential distribution, we can consider its mean value $\left(m_{\tau \text { wet }}\right)$ as a representative value of this distribution. The results are collected in Table 3.

(ii) The distribution of dry periods called "dry distribution": in this case the assumption is that the variable "consecutive number of dry days" $\left(\tau_{\text {dry }}\right)$ is characterized by a Weibull distribution; therefore, it can be represented by its mean value $\left(m_{\tau \mathrm{dry}}\right)$ and its exponent $(k)$. The results are collected in Table 3 .

(iii) The "mean of intensities distribution": assuming that the variable "average intensity of each storm" is characterized by an exponential distribution, we can consider its mean value $\left(m_{I}\right)$ as a representative value of this distribution. The results are collected in Table 3.

In particular, to assess the average intensity in the distribution of synoptic events, the relationship proposed by Veneziano and Iacobellis [22] was considered:

$$
m_{I}=R \cdot \frac{m_{\tau \text { wet }}+m_{\tau \mathrm{dry}}}{m_{\tau \mathrm{wet}}},
$$

where $R$ is the mean annual hourly rainfall intensity over the entire investigated period: $R=h_{\text {tot }} /(365 \times 24)$ and $h_{\text {tot }}$ is the total annual precipitation mean value for each rain gauge station.

Table 3 shows all the parameters of the exterior model, obtained as mentioned above, and the total annual mean value of precipitation $\left(h_{\text {tot }}\right)$ for each rain gauge station in Puglia.

In this work, we assumed that the parameter, $C_{1}$, related to the multifractality of the interior process of IRP, is equal to 0.1 , being the general best fit value reported in the literature (e.g., [22]). The seasonal variation of such parameters, investigated by Portoghese et al. [55], was also not considered in this paper.

After identifying the parameters of the exterior process, the correlation between $m_{\tau \text { dry }}$ and $h_{\text {tot }}$ parameters, that characterize respectively dry and wet intervals (Figure 2), was found.

In order to identify the different values of these parameters that represent different rainfall patterns which can be found in Puglia, the area of the plot $\left[m_{\tau \mathrm{dry}}-h_{\mathrm{tot}}\right]$ was divided into three equiprobable classes on the base of $m_{\tau \text { dry }}$ values and into other three equiprobable classes on the base of $h_{\text {tot }}$. In this case nine classes were obtained, as shown in Figure 2.

Identification of nine climatic classes representing different rainfall patterns in Puglia. The Thiessen polygons of the investigated rainfall stations were used to trace these climatic areas thus obtaining the map in Figure 3.

On the base of the relationship between $m_{\tau \mathrm{dry}}$ and $h_{\text {tot }}$ parameters, nine classes having different rainfall features were identified, as shown in the following matrix reported in Figure 4(a), in which each climatic class was symbolized by different colors: red color was used to represent the class with low $h_{\text {tot }}$ values, blue color was used to represent the class 
TABLE 3: Parameters of the exterior model.

\begin{tabular}{|c|c|c|c|c|c|c|c|}
\hline Basin & Number & Name & $m_{\mathrm{dry}}[\mathrm{h}]$ & $k$ & $m_{\text {wet }}[\mathrm{h}]$ & $m_{I}[\mathrm{~mm} / \mathrm{h}]$ & $h_{\text {tot }}[\mathrm{mm}]$ \\
\hline \multirow{2}{*}{ Lesina Lake } & 1 & Lesina & 91,0516 & 0,7125 & 24,3482 & 0,3159 & 637,9 \\
\hline & 2 & Sannicandro Garganico & 93,0884 & 0,7305 & 27,9399 & 0,3817 & 804,8 \\
\hline Varano Lake & 3 & Cagnano Varano & 87,8152 & 0,7218 & 27,0604 & 0,3545 & 816,0 \\
\hline \multirow{4}{*}{ Various basins } & 4 & Vico del Gargano & 86,9864 & 0,7544 & 27,0476 & 0,3593 & 777,0 \\
\hline & 5 & Vieste & 104,3825 & 0,7205 & 24,0248 & 0,3142 & 570,1 \\
\hline & 6 & Bosco Umbra & 71,8175 & 0,7139 & 34,6593 & 0,3512 & 1160,3 \\
\hline & 7 & Monte S.Angelo & 77,6689 & 0,6978 & 29,7351 & 0,2733 & 774,1 \\
\hline \multirow{16}{*}{ Candelaro } & 8 & Torremaggiore & 90,6646 & 0,6641 & 22,8815 & 0,2723 & 585,3 \\
\hline & 9 & S.Severo & 91,2114 & 0,707 & 22,3729 & 0,2675 & 514,9 \\
\hline & 10 & S.Marco in Lamis & 74,9043 & 0,6723 & 31,0812 & 0,3073 & 905,8 \\
\hline & 11 & Mass. Pidocchiara & 80,8978 & 0,6377 & 22,6061 & 0,2479 & 527,4 \\
\hline & 12 & Pietramontecorvino & 72,4838 & 0,6632 & 27,45 & 0,3179 & 872,0 \\
\hline & 13 & Pietramontecorvino (Eaap) & 85,0966 & 0,6882 & 22,4847 & 0,2663 & 539,9 \\
\hline & 14 & Volturino & 81,9527 & 0,6728 & 24,381 & 0,2626 & 651,5 \\
\hline & 15 & Alberona & 69,7892 & 0,6669 & 31,085 & 0,2792 & 849,4 \\
\hline & 16 & Tertiveri & 82,1544 & 0,6585 & 25,7195 & 0,2523 & 559,0 \\
\hline & 17 & Orto di Zolfo & 57,7321 & 0,6339 & 32,8889 & 0,255 & 879,7 \\
\hline & 18 & Lucera & 81,526 & 0,6903 & 23,1071 & 0,2484 & 594,3 \\
\hline & 19 & Biccari & 80,3834 & 0,7105 & 29,1397 & 0,2998 & 791,0 \\
\hline & 20 & Faeto (S.Vito) & 68,2987 & 0,6672 & 33,2925 & 0,2618 & 799,0 \\
\hline & 21 & Troia & 89,6227 & 0,7368 & 24,79 & 0,2943 & 653,3 \\
\hline & 22 & Foggia oss. & 91,1316 & 0,7185 & 21,1423 & 0,2762 & 467,5 \\
\hline & 23 & Foggia iac & 100,6901 & 0,7279 & 20,0741 & 0,2675 & 410,6 \\
\hline \multirow{5}{*}{ Salso-Salpi-Celentano } & 24 & S.Giovanni Rotondo & 78,8768 & 0,7029 & 27,041 & 0,3245 & 813,3 \\
\hline & 25 & Manfredonia & 81,9479 & 0,6444 & 21,1135 & 0,2159 & 448,8 \\
\hline & 26 & Fonte Rosa & 72,3978 & 0,6472 & 20,4555 & 0,2189 & 448,4 \\
\hline & 27 & Cerignola & 74,9811 & 0,6687 & 22,4028 & 0,2584 & 560,9 \\
\hline & 28 & Mass. S.Chiara & 87,1738 & 0,6821 & 20,9691 & 0,2537 & 465,5 \\
\hline \multirow{9}{*}{ Cervaro, Carapelle } & 29 & Savignano di Puglia & 70,3321 & 0,6726 & 28,9864 & 0,262 & 733,3 \\
\hline & 30 & Monteleone di Puglia & 58,7039 & 0,6668 & 31,8446 & 0,2462 & 819,5 \\
\hline & 31 & Orsara di Puglia & 72,7858 & 0,6694 & 29,7488 & 0,3103 & 878,0 \\
\hline & 32 & Bovino & 63,9046 & 0,6573 & 27,8255 & 0,2952 & 819,2 \\
\hline & 33 & Castelluccio dei Sauri & 89,1752 & 0,7275 & 22,6852 & 0,2933 & 528,5 \\
\hline & 34 & Bisaccia & 59,2551 & 0,6322 & 29,0387 & 0,2539 & 530,5 \\
\hline & 35 & S.Agata di Puglia & 86,2517 & 0,6858 & 22,5079 & 0,2583 & 531,4 \\
\hline & 36 & Ascoli Satriano & 77,7202 & 0,6621 & 23,5389 & 0,283 & 619,6 \\
\hline & 37 & Ortanova scalo & 98,4128 & 0,708 & 19,8689 & 0,2774 & 446,0 \\
\hline \multirow{25}{*}{ Ofanto } & 38 & Nusco & 57,0676 & 0,579 & 36,0346 & 0,2994 & 820,6 \\
\hline & 39 & Lioni & 26,4681 & 0,4782 & 32,4311 & 0,1738 & 948,5 \\
\hline & 40 & S.Angelo dei Lombardi & 53,0217 & 0,5726 & 32,5761 & 0,256 & 952,0 \\
\hline & 41 & Teora & 49,6926 & 0,5937 & 36,3906 & 0,2752 & 1012,8 \\
\hline & 42 & Andretta & 54,0938 & 0,6216 & 32,0935 & 0,2185 & 821,4 \\
\hline & 43 & Pescopagano & 66,308 & 0,6851 & 35,3984 & 0,3222 & 1091,9 \\
\hline & 44 & Calitri & 61,3074 & 0,6515 & 29,8333 & 0,2498 & 769,8 \\
\hline & 45 & S.Fele & 61,3794 & 0,6295 & 37,7991 & 0,2634 & 925,0 \\
\hline & 46 & Castel Lago Pesole & 56,2687 & 0,6242 & 32,1645 & 0,2761 & 905,6 \\
\hline & 47 & Atella & 52,6494 & 0,587 & 27,3338 & 0,1989 & 661,0 \\
\hline & 48 & Lacedonia & 70,4878 & 0,7031 & 28,463 & 0,2689 & 780,4 \\
\hline & 49 & Monticchio Bagni & 55,9144 & 0,6263 & 31,5205 & 0,2537 & 820,3 \\
\hline & 50 & Rocchetta S.Antonio scalo & 80,627 & 0,6756 & 23,5446 & 0,2903 & 673,4 \\
\hline & 51 & Ripacandida & 73,4722 & 0,7075 & 27,0046 & 0,2611 & 656,6 \\
\hline & 52 & Melfi & 61,6199 & 0,652 & 28,4248 & 0,2884 & 843,5 \\
\hline & 53 & Forenza & 66,7412 & 0,6813 & 29,2743 & 0,2338 & 683,4 \\
\hline & 54 & Venosa & 74,0361 & 0,674 & 26,8496 & 0,2788 & 710,5 \\
\hline & 55 & Diga sul Rendina & 74,6143 & 0,6763 & 24,0994 & 0,2668 & 585,4 \\
\hline & 56 & Lavello & 80,952 & 0,6991 & 22,8191 & 0,2833 & 598,2 \\
\hline & 57 & Loconia & 75,1722 & 0,6582 & 20,9225 & 0,2476 & 506,2 \\
\hline & 58 & Borgo Libertà & 85,8346 & 0,6979 & 22,9415 & 0,2718 & 563,3 \\
\hline & 59 & Spinazzola & 69,4975 & 0,6555 & 25,1559 & 0,2521 & 655,4 \\
\hline & 60 & Montemilone & 82,8718 & 0,6575 & 23,4572 & 0,2769 & 596,5 \\
\hline & 61 & Minervino Murge & 81,175 & 0,6653 & 23,7927 & 0,2792 & 584,0 \\
\hline & 62 & Canosa di Puglia & 89,0553 & 0,6814 & 22,1361 & 0,2995 & 542,2 \\
\hline
\end{tabular}


TABle 3: Continued.

\begin{tabular}{|c|c|c|c|c|c|c|c|}
\hline Basin & Number & Name & $m_{\mathrm{dry}}[\mathrm{h}]$ & $k$ & $m_{\text {wet }}[\mathrm{h}]$ & $m_{I}[\mathrm{~mm} / \mathrm{h}]$ & $h_{\text {tot }}[\mathrm{mm}]$ \\
\hline \multirow{31}{*}{ Murge } & 63 & Barletta & 94,0299 & 0,6835 & 21,3386 & 0,2885 & 522,2 \\
\hline & 64 & Andria & 82,7299 & 0,6608 & 22,6215 & 0,2715 & 577,4 \\
\hline & 65 & Castel del Monte & 59,5571 & 0,5816 & 26,2625 & 0,2022 & 640,2 \\
\hline & 66 & Corato & 86,5411 & 0,6884 & 21,7316 & 0,3073 & 538,5 \\
\hline & 67 & Bisceglie & 88,0699 & 0,6865 & 22,5811 & 0,2732 & 578,5 \\
\hline & 68 & Ruvo di Puglia & 82,6408 & 0,6514 & 22,7895 & 0,2726 & 599,1 \\
\hline & 69 & Giovinazzo & 96,5196 & 0,688 & 22,713 & 0,2966 & 536,8 \\
\hline & 70 & Quasano & 70,8268 & 0,6391 & 21,9957 & 0,2369 & 560,1 \\
\hline & 71 & Bitonto & 80,5965 & 0,6217 & 22,2512 & 0,2827 & 585,4 \\
\hline & 72 & Altamura & 63,6599 & 0,6249 & 25,0068 & 0,2056 & 549,1 \\
\hline & 73 & Grumo Appula & 72,9712 & 0,6009 & 22,5292 & 0,2677 & 571,7 \\
\hline & 74 & Bari sez. idrografica & 86,7493 & 0,6384 & 21,6093 & 0,2921 & 514,2 \\
\hline & 75 & Bari osservatorio & 91,2586 & 0,652 & 22,2619 & 0,2829 & 532,7 \\
\hline & 76 & Bari fac. ingegneria & 85,9745 & 0,6054 & 24,3858 & 0,2342 & 520,1 \\
\hline & 77 & Mercadante & 53,8352 & 0,5726 & 27,4403 & 0,2035 & 645,2 \\
\hline & 78 & Cassano delle Murge & 85,0081 & 0,6569 & 24,8709 & 0,2878 & 658,9 \\
\hline & 79 & Adelfia Canneto & 88,6833 & 0,6604 & 25,1834 & 0,2765 & 589,8 \\
\hline & 80 & Casamassima & 83,569 & 0,6284 & 24,3611 & 0,2539 & 562,6 \\
\hline & 81 & Santeramo in Colle & 77,145 & 0,6174 & 23,4071 & 0,2627 & 636,7 \\
\hline & 82 & Gioia del Colle & 63,9207 & 0,5979 & 24,4868 & 0,2559 & 628,1 \\
\hline & 83 & Turi & 74,1393 & 0,62 & 23,8318 & 0,2553 & 604,3 \\
\hline & 84 & Conversano & 79,9444 & 0,6242 & 23,9081 & 0,2839 & 625,6 \\
\hline & 85 & Polignano a Mare & 86,8408 & 0,6304 & 25,0996 & 0,2772 & 583,3 \\
\hline & 86 & Castellana Grotte & 54,4983 & 0,5488 & 26,109 & 0,2017 & 657,3 \\
\hline & 87 & Noci & 59,7421 & 0,57 & 24,2529 & 0,2232 & 662,6 \\
\hline & 88 & Fasano & 95,8643 & 0,6718 & 24,809 & 0,3179 & 593,5 \\
\hline & 89 & Locorotondo & 58,3498 & 0,5541 & 28,2275 & 0,2188 & 682,4 \\
\hline & 90 & Ceglie Messapico & 84,1875 & 0,6335 & 25,15 & 0,285 & 659,9 \\
\hline & 91 & Ostuni & 68,4693 & 0,59 & 27,9963 & 0,2737 & 705,2 \\
\hline & 92 & Massafra & 101,113 & 0,7134 & 22,1631 & 0,3251 & 517,3 \\
\hline & 93 & Crispiano & 96,3672 & 0,6822 & 22,4204 & 0,3056 & 546,0 \\
\hline \multirow{28}{*}{ Salento } & 94 & Latiano & 49,8272 & 0,5118 & 25,0408 & 0,1951 & 632,8 \\
\hline & 95 & Brindisi & 82,4609 & 0,6109 & 24,072 & 0,2739 & 600,2 \\
\hline & 96 & S.Pancrazio Salentino & 59,3335 & 0,5466 & 23,8694 & 0,2427 & 639,9 \\
\hline & 97 & S.Pietro Vernotico & 65,7885 & 0,5479 & 25,9981 & 0,2352 & 632,5 \\
\hline & 98 & Novoli & 57,5226 & 0,542 & 28,5556 & 0,2137 & 643,2 \\
\hline & 99 & Lecce & 65,0108 & 0,5575 & 24,9573 & 0,252 & 649,4 \\
\hline & 100 & Melendugno & 58,2878 & 0,4957 & 25,8149 & 0,2177 & 599,9 \\
\hline & 101 & Maglie & 44,9812 & 0,5099 & 28,9804 & 0,2055 & 762,9 \\
\hline & 102 & Otranto & 58,0359 & 0,5765 & 27,4795 & 0,2512 & 787,5 \\
\hline & 103 & Minervino di Lecce & 52,1476 & 0,5234 & 28,4833 & 0,2456 & 826,6 \\
\hline & 104 & Vignacastrisi & 42,8536 & 0,5003 & 30,9247 & 0,2016 & 783,8 \\
\hline & 105 & Ruffano & 61,7285 & 0,5466 & 25,591 & 0,2786 & 773,5 \\
\hline & 106 & S.Maria di Leuca & 51,7732 & 0,4824 & 25,1729 & 0,2297 & 691,1 \\
\hline & 107 & Presicce & 57,1893 & 0,5352 & 26,2804 & 0,2684 & 794,0 \\
\hline & 108 & Taviano & 68,846 & 0,5572 & 24,6328 & 0,2502 & 604,7 \\
\hline & 109 & Collepasso & 63,6108 & 0,5369 & 25,7089 & 0,2487 & 626 \\
\hline & 110 & Gallipoli & 79,4586 & 0,5756 & 22,503 & 0,2782 & 563,7 \\
\hline & 111 & Galatina & 52,8941 & 0,5133 & 28,5291 & 0,2193 & 692,2 \\
\hline & 112 & Nardo’ & 69,2597 & 0,5553 & 25,1713 & 0,2412 & 596,2 \\
\hline & 113 & Copertino & 76,4832 & 0,5776 & 25,7796 & 0,2675 & 629,5 \\
\hline & 114 & Mass. Monteruga & 44,6302 & 0,5079 & 25,9965 & 0,1839 & 615,6 \\
\hline & 115 & Avetrana & 86,3732 & 0,6812 & 23,0938 & 0,3007 & 600,6 \\
\hline & 116 & Manduria & 77,4516 & 0,6252 & 22,469 & 0,2852 & 620,8 \\
\hline & 117 & Lizzano & 98,8352 & 0,6858 & 21,0276 & 0,3244 & 556,5 \\
\hline & 118 & Grottaglie & 84,3978 & 0,6246 & 22,1172 & 0,2761 & 529,0 \\
\hline & 119 & S.Giorgio Jonico & 86,2638 & 0,6117 & 21,4668 & 0,2953 & 561,9 \\
\hline & 120 & Taranto & 106,3039 & 0,6766 & 20,4759 & 0,3378 & 471,6 \\
\hline & 121 & Talsano & 82,1817 & 0,6126 & 20,9189 & 0,2432 & 421,3 \\
\hline \multirow{3}{*}{ Lato and Galeso } & 122 & Castellaneta & 90,1218 & 0,7498 & 22,7253 & 0,3095 & 556,8 \\
\hline & 123 & Ginosa & 104,3585 & 0,7044 & 22,3677 & 0,3253 & 597,9 \\
\hline & 124 & Ginosa Marina & 61,2166 & 0,569 & 22,8324 & 0,2099 & 545,5 \\
\hline
\end{tabular}


TABLE 4: Rain gauges belonging to five climatic subareas with their characteristics.

\begin{tabular}{|c|c|c|c|c|c|c|c|c|c|c|c|c|c|c|c|c|c|c|c|c|c|c|}
\hline Area & & & & & & & & & & & & mbes & & & & & & & & & & \\
\hline 1 & 34 & 72 & 124 & & & & & & & & & & & & & & & & & & & \\
\hline \multirow{2}{*}{2} & 5 & 9 & 13 & 22 & 23 & 28 & 33 & 35 & 37 & 58 & 62 & 63 & 64 & 66 & 67 & 69 & 74 & 75 & 76 & 80 & 85 & 92 \\
\hline & 93 & 117 & 118 & 119 & 120 & 122 & & & & & & & & & & & & & & & & \\
\hline 3 & 14 & 18 & 36 & 51 & 55 & 56 & 59 & 61 & 71 & 81 & 83 & 84 & 95 & 108 & 112 & 113 & 116 & & & & & \\
\hline 4 & 2 & 3 & 4 & & & & & & & & & & & & & & & & & & & \\
\hline \multirow{2}{*}{5} & 17 & 30 & 32 & 38 & 39 & 40 & 41 & 42 & 43 & 44 & 45 & 46 & 49 & 52 & 53 & 89 & 101 & 102 & 103 & 104 & 105 & 106 \\
\hline & 107 & 111 & & & & & & & & & & & & & & & & & & & & \\
\hline
\end{tabular}

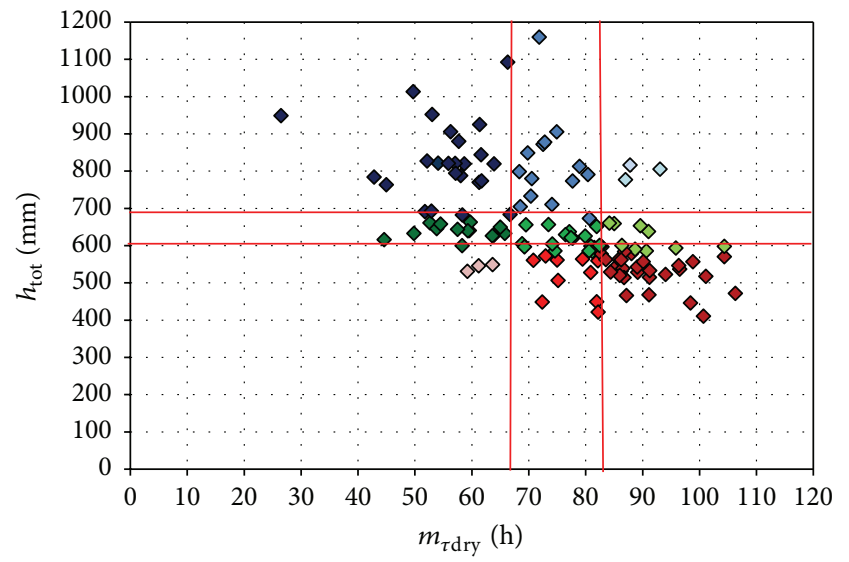

Figure 2: Identification of nine climatic classes representing different rainfall patterns in Puglia.

with high $h_{\text {tot }}$ values, and green color was used to represent the class with mean values of $h_{\text {tot }}$. Then different shades of these three colors were used in order to better identify the nine classes; for instance, dark red symbolizes the least rainy areas (low values of $h_{\text {tot }}$ and high values of $m_{\tau \text { dry }}$ ), while dark blue represents the most rainy areas (high values of $h_{\text {tot }}$ and low values of $\left.m_{\tau \text { dry }}\right)$.

In order to reach the aim of this work, that is, to extend the stormwater quality to ungauged areas, a smaller number of classes can be considered. Therefore, among these nine classes, four classes that represent the four extreme conditions and one that represents the central condition were taken into account and they are reported in Figure 4(b):

Area 1 (light red): characterized by a low value of total annual precipitation $\left(h_{\text {tot }}\right)$ and a low value of mean of consecutive number of dry days $\left(m_{\tau \text { dry }}\right)$;

Area 2 (dark red): characterized by precipitation with a low $h_{\text {tot }}$ and high $m_{\tau \text { dry }}$; this is a typical arid zone;

Area 4 (dark blue): characterized by precipitation with a high $h_{\text {tot }}$ and low $m_{\tau \text { dry }}$; this is a typical wet zone;

Area 5 (light blue): characterized by precipitation with a high $h_{\text {tot }}$ and high $m_{\tau \text { dry }}$.

And finally
Area 3 (green) was considered, in order to have a central condition, characterized by mean values of $h_{\text {tot }}$ and $m_{\tau \text { dry }}$.

All the other classes excluded from the current work represent other average conditions that reveal information which can be located among the results obtained from the classes considered.

In both matrices, the numbers 1, 2, and 3 represent low, medium, and high value of each parameter, respectively.

For each of five classes, we considered only the rain gauge station characterized by the longest time series of precipitation ( 44 years) and that represents the centroid of the cluster of each climatic subarea, being, in this way, the most representative station of its own class (Figure 3 ):

(i) Ginosa Marina for Area 1;

(ii) Barletta for Area 2;

(iii) Manduria for Area 3;

(iv) Presicce for Area 4;

(v) Cagnano Varano for Area 5.

It is well known that the representative point of a cluster, or cluster center for the $k$-means algorithm, is the componentwise mean of the points in its cluster, chosen for minimizing the within cluster variances (minimizing within the cluster the squared Euclidean distance).

In Table 4 the rain gauges belonging to each of five classes are reported. They are represented with the same correspondent numbers of Table 3 .

Since the main objective of the proposed research is to evaluate stormwater quality including pollutographs and their characteristics in ungauged basins, synthetic scenarios of precipitation were generated in Matlab environment and then input to SWMM model. The characteristics of the rainfall data were reproduced using series with time step of 15 minutes of aggregation (which is the reference time provided by Italian Legislation [56] for first flush analysis) and length of 10 years. In order to provide information about qualitative characteristics of runoff, it was necessary to introduce in the model the characteristics of the catchments and of the drainage network. For this purpose, in the following phase $\mathrm{C}$, the different case studies are presented. 
TABLE 5: "Nontraditional” parameters of ungauged basins.

\begin{tabular}{|c|c|c|c|c|c|c|c|c|c|c|}
\hline \multirow{2}{*}{ Parameters } & \multicolumn{10}{|c|}{ Ungauged basins } \\
\hline & \multicolumn{2}{|c|}{ Barletta } & \multicolumn{2}{|c|}{ Manduria } & \multicolumn{2}{|c|}{ Cagnano Varano } & \multicolumn{2}{|c|}{ Presicce } & \multicolumn{2}{|c|}{ Ginosa Marina } \\
\hline Area [ha] & \multicolumn{2}{|c|}{30.18} & \multicolumn{2}{|c|}{31.5} & \multicolumn{2}{|c|}{20.11} & \multicolumn{2}{|c|}{30.78} & \multicolumn{2}{|c|}{31.45} \\
\hline \multirow{8}{*}{ Width $[\mathrm{m}]$} & & & & & & & & & Sub. 1 & 519.88 \\
\hline & & & & & Sub. 1 & 531.26 & & & Sub. 2 & 522.08 \\
\hline & Sub. 1 & 379.88 & Sub. 1 & 318.06 & Sub. 2 & 130.18 & & & Sub. 3 & 38.1 \\
\hline & Sub. 2 & 1001.68 & Sub. 2 & 815.4 & Sub. 3 & 453.7 & Sub. 1 & 527.1 & Sub. 4 & 324.78 \\
\hline & Sub. 3 & 728.08 & Sub. 3 & 581.5 & Sub. 4 & 550.52 & Sub. 2 & 845.36 & Sub. 5 & 232.6 \\
\hline & & & & & Sub. 5 & 236.48 & & & Sub. 6 & 327.92 \\
\hline & & & & & Sub. 6 & 550.88 & & & Sub. 7 & 194.46 \\
\hline & & & & & & & & & Sub. 8 & 1567.68 \\
\hline Slope [\%] & \multicolumn{2}{|c|}{0.16} & \multicolumn{2}{|c|}{0.97} & \multicolumn{2}{|c|}{0.5} & \multicolumn{2}{|c|}{0.08} & \multicolumn{2}{|c|}{0.09} \\
\hline \% Imperv [\%] & \multicolumn{2}{|c|}{93} & \multicolumn{2}{|c|}{81.69} & \multicolumn{2}{|c|}{74.95} & \multicolumn{2}{|c|}{30.73} & \multicolumn{2}{|c|}{48.98} \\
\hline Roughness $\left[\mathrm{s} / \mathrm{m}^{1 / 3}\right]$ & \multicolumn{2}{|c|}{0.013} & \multicolumn{2}{|c|}{0.013} & \multicolumn{2}{|c|}{0.013} & \multicolumn{2}{|c|}{0.013} & \multicolumn{2}{|c|}{0.013} \\
\hline
\end{tabular}

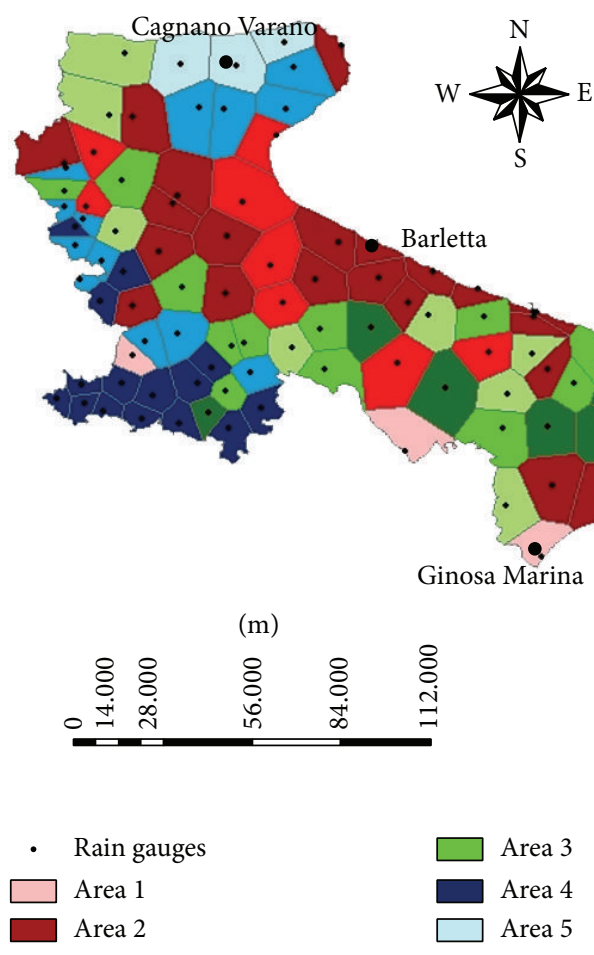

FIGURE 3: Representation of the climatic subareas identified on the base of the correlations between parameters of IRP model: $m_{\tau \mathrm{dry}}$ and $h_{\text {tot }}$.

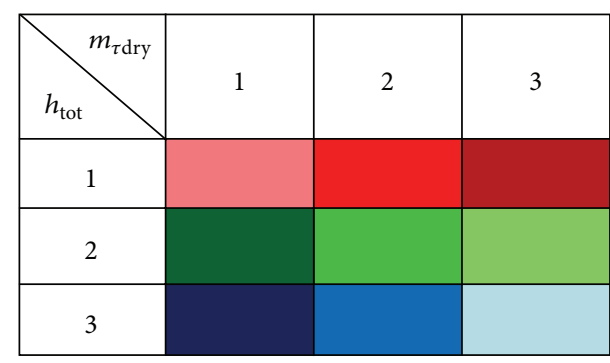

(a)

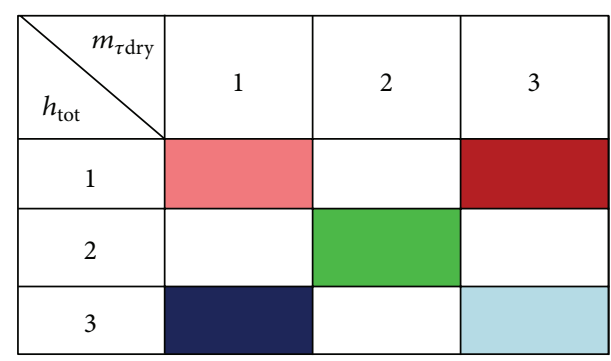

(b)

FIgURE 4: (a) Matrix of nine climatic subareas. (b) Matrix of five climatic subareas chosen. 


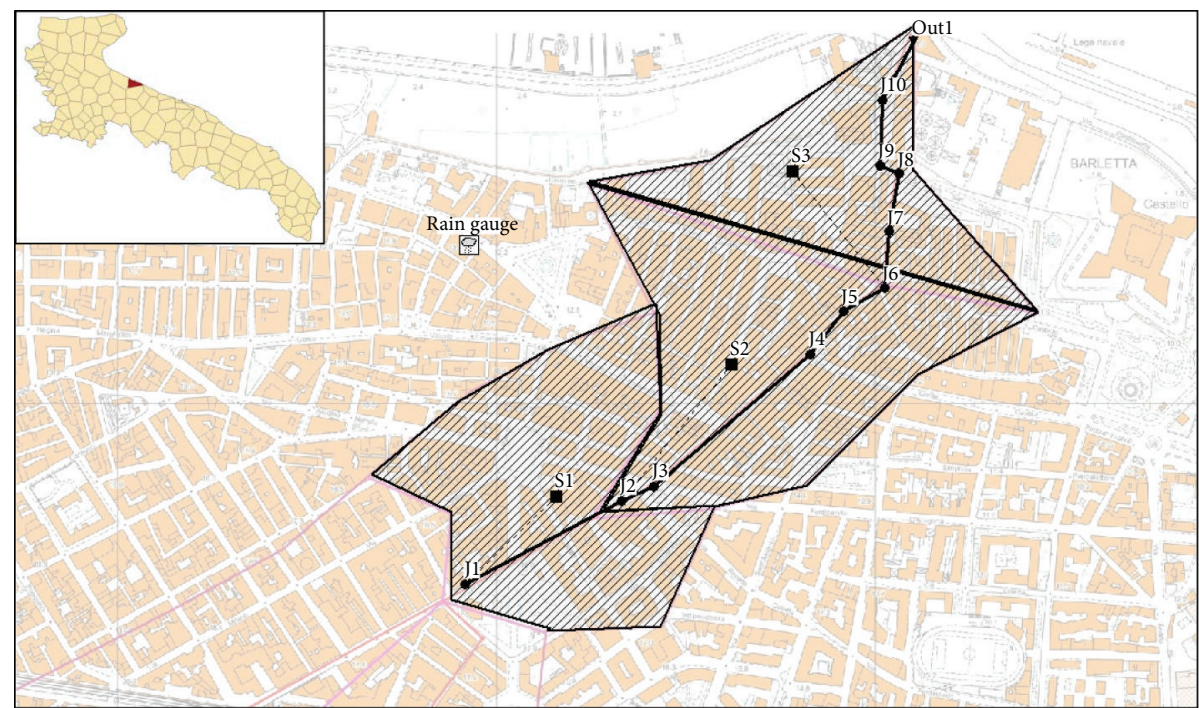

Figure 5: Barletta basin and representation of sewer system.

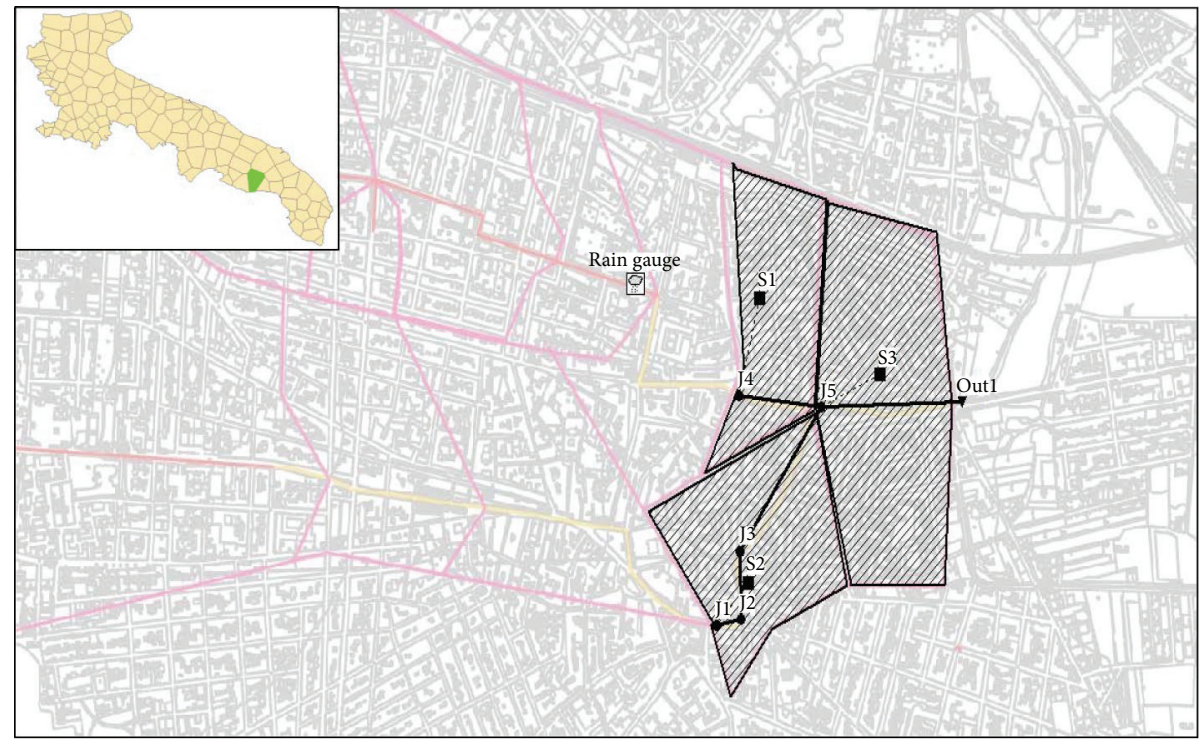

Figure 6: Manduria basin and representation of sewer system.

\section{Phase C: Exporting Calibration Parameters in Ungauged Basins: The Case Studies of Barletta, Manduria, Cagnano Varano, Presicce, and Ginosa Marina}

In Barletta the total area of the drainage basin is equal to 30.18 ha with a percentage of impervious surface equal to $93 \%(28.17 \mathrm{ha})$. The average slope of the basin is $0.16 \%$. In particular, the land use thematic map, extracted from the regional geographical information system (SIT Puglia), shows that the entire area is exclusively residential.

The sewage system, used exclusively for the collection of rainwater, has a total length of $1054.85 \mathrm{~m}$.
Figure 5 shows the SWMM scheme of the basin including 3 subcatchments and a drainage network with 10 nodes (black dots) and 10 channels (black solid lines).

The sewer system in Manduria has a total drainage basin of 31.85 ha with a percentage of impervious surface equal to $81.69 \%$ ( $25.73 \mathrm{ha}$ ). The average slope of the basin is $0.97 \%$; the land use map shows that the entire area is residential.

In this basin the sewage system, used exclusively for the collection of rainwater, is composed by circular concrete conduits for a total length of $857.48 \mathrm{~m}$.

Figure 6 shows the SWMM scheme of the basin including 3 subcatchments and a drainage network with 5 nodes (black dots) and 5 channels (black solid lines). 


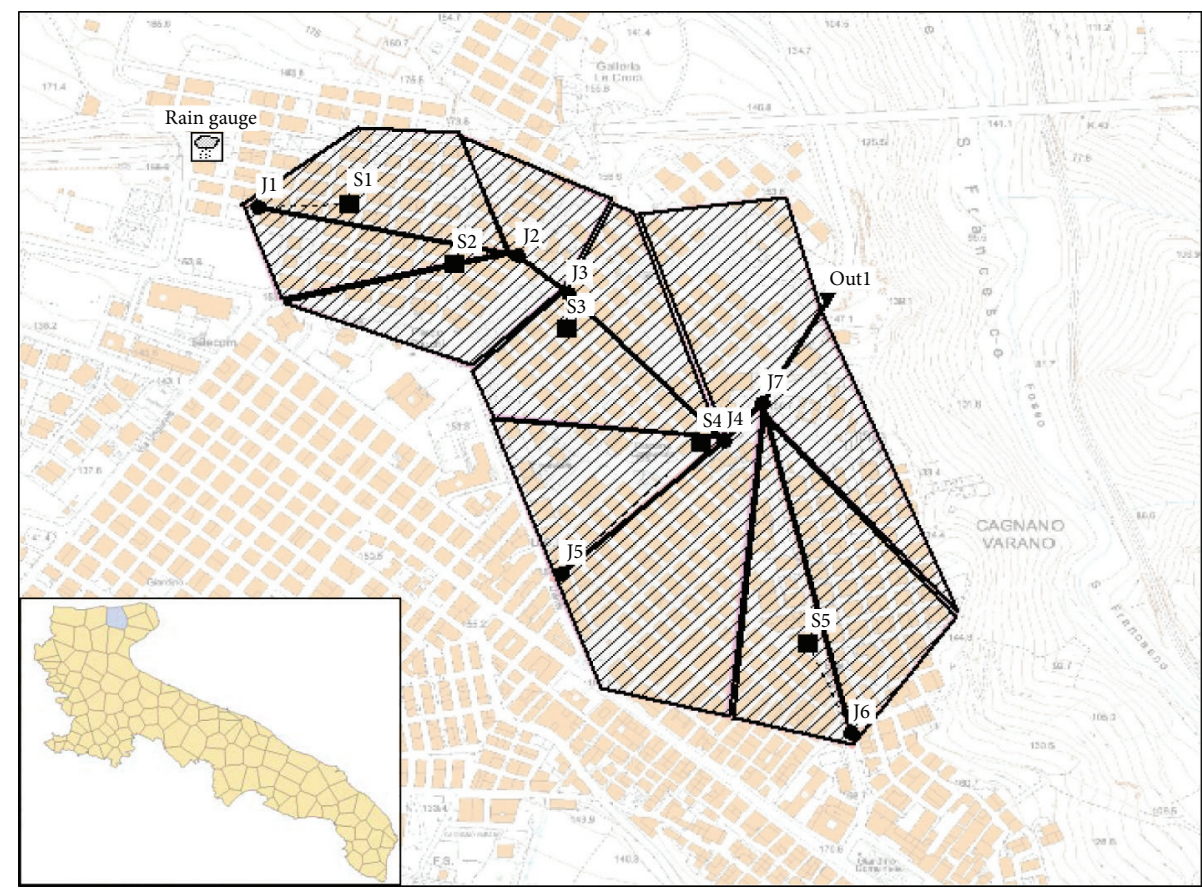

Figure 7: SWMM depiction of Cagnano Varano basin with its drainage network.

The total contributing area of Cagnano Varano catchment above the gauging station is $20.11 \mathrm{ha}$, and $74.95 \%$ ( $15.07 \mathrm{ha}$ ) of the total area is residential with impervious surface. The average slope of the basin is $0.5 \%$. A total of 6 subcatchments are delineated within the watershed. All surface flow is collected at the watershed outlet after routing through 7 conduits, whose total length is equal to $1326.51 \mathrm{~m}$.

Figure 7 illustrates the SWMM depiction of the Cagnano Varano watershed.

In Presicce the catchment has a total surface of 30.78 ha with $30.73 \%$ ( 9.45 ha) of impervious area characterized by residential land use like the previous basins. The average slope of the basin is equal to $0.08 \%$. The catchment area is covered by a main sewer which is circular and has a diameter of $2.2 \mathrm{~m}$ in the initial section and $2.4 \mathrm{~m}$ in the final section. The estimated length of this sewer is $306.23 \mathrm{~m}$ up to the downstream point.

Figure 8 illustrates the SWMM depiction of the basin including 2 subcatchments and a drainage network with 3 nodes (black dots) and 3 channels (black solid lines).

The basin located in Ginosa Marina has total contributing area equal to $31.45 \mathrm{ha}$, of which the $48.98 \%$ ( $15.40 \mathrm{ha})$ is impervious and destined to residential use. The average slope of the watershed is equal to $0.09 \%$. The discretization of the catchment provides 8 subcatchments. The surface runoff flows through a drainage network of $1695.09 \mathrm{~m}$ long.

In Figure 9, the SWMM depiction of the subcatchment is shown.

As already explained in Section 2.2, we considered these five catchments, because they are characterized by values of "Nontraditional" calibration parameters that may be considered similar to those estimated for Sannicandro di Bari in [24]. In Table 5, these parameters catchment are listed.

\section{Coupling IRP with SWMM Model for Pollutograph Evaluation and Discussion}

In this section a pollutographs evaluation in all the investigated ungauged sites by coupling IRP and SWMM model is reported. In particular, by using the IRP model, time series of precipitation of a given length were generated in order to be implemented in SWMM. The estimated parameters used in SWMM model were

(i) the "Traditional" and qualitative parameters already evaluated for the case study of Sannicandro di Bari, where a monitoring campaign is avalaible;

(ii) the "Nontraditional" parameters, calculated for the investigated case studies of Barletta, Manduria, Cagnano Varano, Presicce, and Ginosa Marina, starting from the catchment characteristics.

As already explained in Section 3.1, the IRP model consists of six parameters derived from the study of the precipitation process aggregate in the exterior and interior processes. The exterior process is characterized by four parameters, the average of the intervals of rain $\left(m_{\tau \text { wet }}\right)$, the mean and the exponent of the Weibull distribution for the dry intervals $(k$ and $\left.m_{\tau \text { dry }}\right)$, and the average of rainfall intensity $\left(m_{I}\right)$, while for the definition of the interior process two other parameters related to its multifractality are introduced, $C_{1}$ and $r$. For Barletta, Manduria, Cagnano Varano, Presicce, and Ginosa Marina basins, the values of these parameters are listed in bold in Table 3 .

Figure 10 shows, for the case study of Barletta, the generated synthetic scenarios of precipitation; a series of 15 minutes of aggregation and length of 10 years was used. 


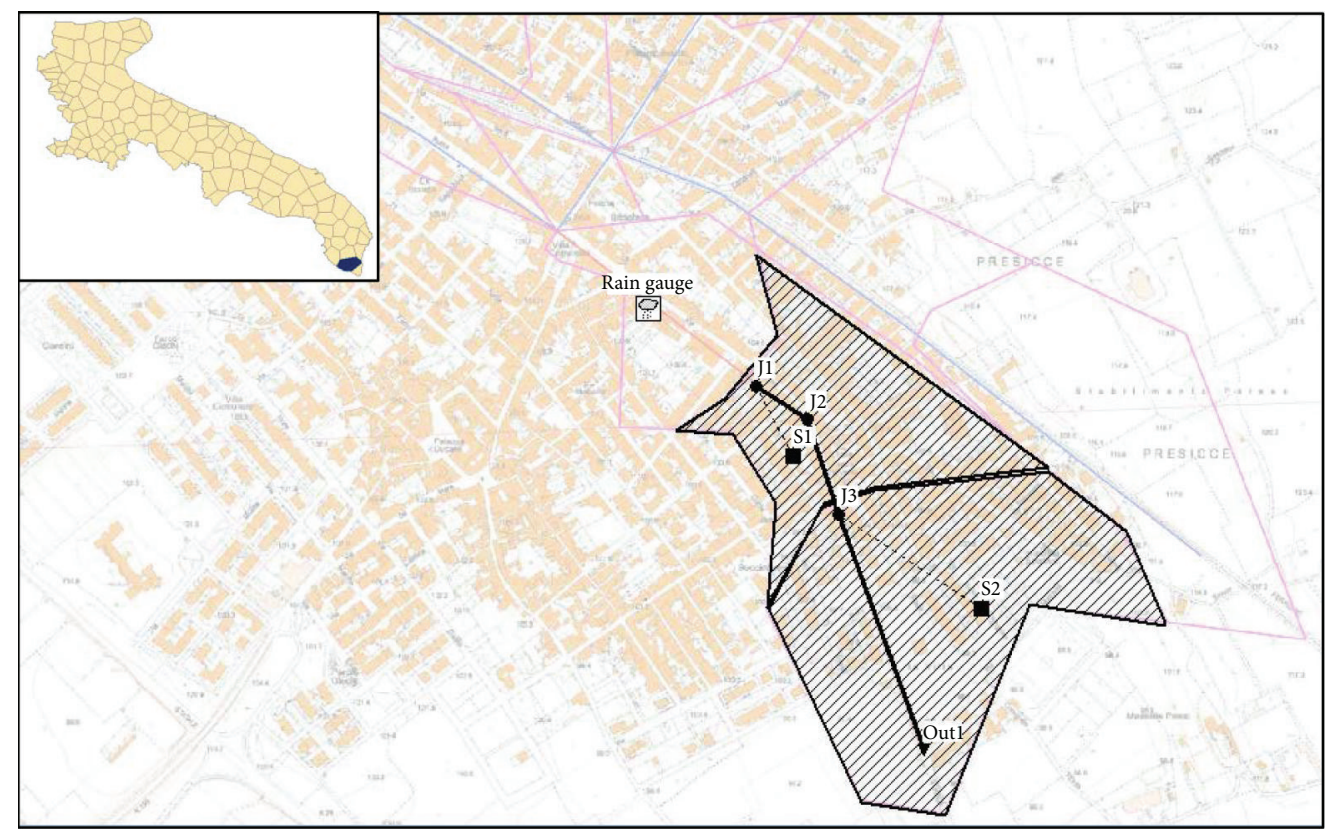

FIgURE 8: SWMM depiction of Presicce basin with its drainage network.

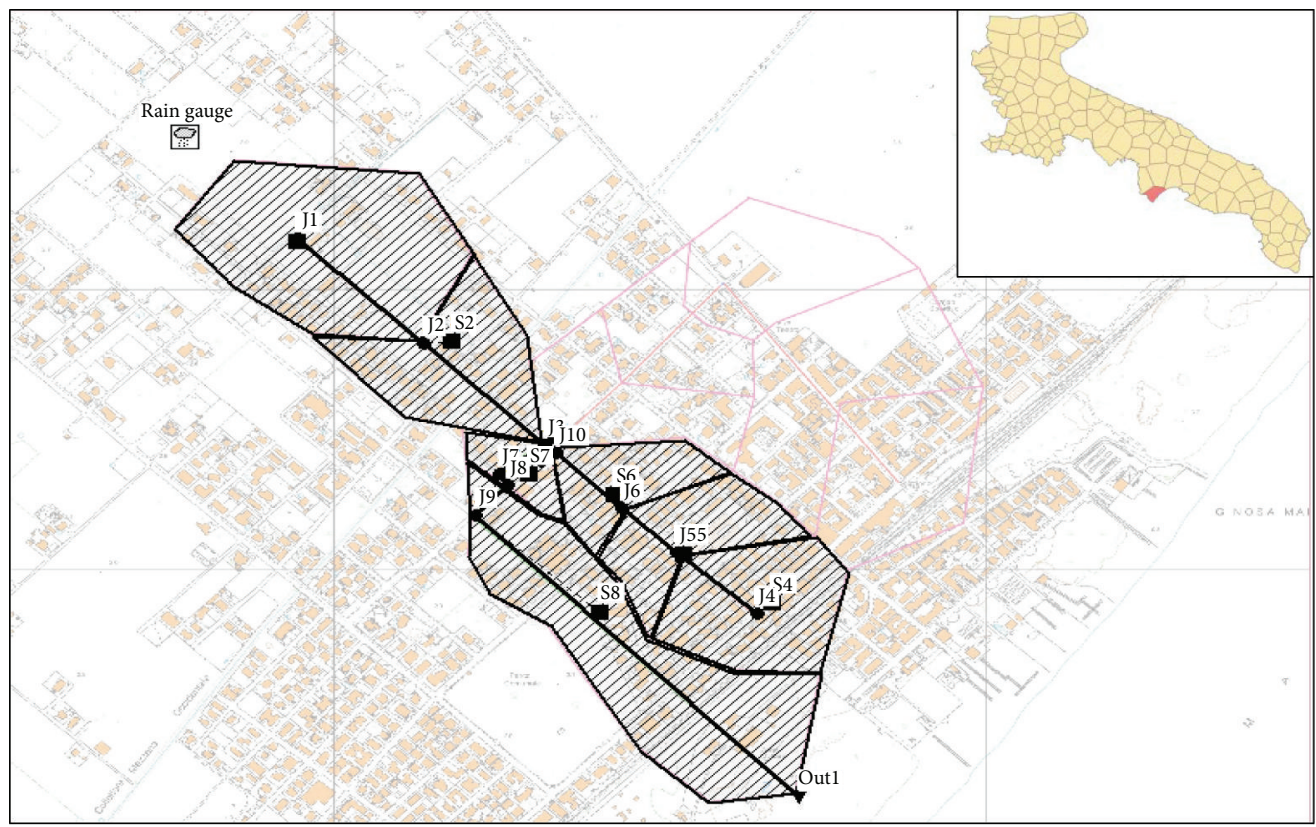

FIGURE 9: SWMM depiction of Ginosa Marina basin with its drainage network.

The hyetographs shown in Figure 10 was implemented in SWMM model for the TSS pollutographs evaluation (Figure 11). Due to the high affinity of many contaminants with solid matter, in the present study only the TSS prediction was taken into account. In fact, several works in literature $[57,58]$ consider TSS as a synthetic index of the general level of pollution in urban areas. For this reason, TSS are often used in mathematical models that simulate the dynamics of polluttants in urban runoff.
The analysis of the distribution of pollutant mass versus volume in stormwater discharges in dimensionless terms by using the so-called " $M(V)$ curves" [59] was performed on the five case studies investigated. This representation provides the variation of the cumulative pollutant mass divided by the total pollutant mass in relation to the cumulative volume divided by the total volume. If the concentration remains constant during the storm event, the pollutant mass is proportional to the volume and the $M(V)$ curve is merged with the $1: 1$ line. 


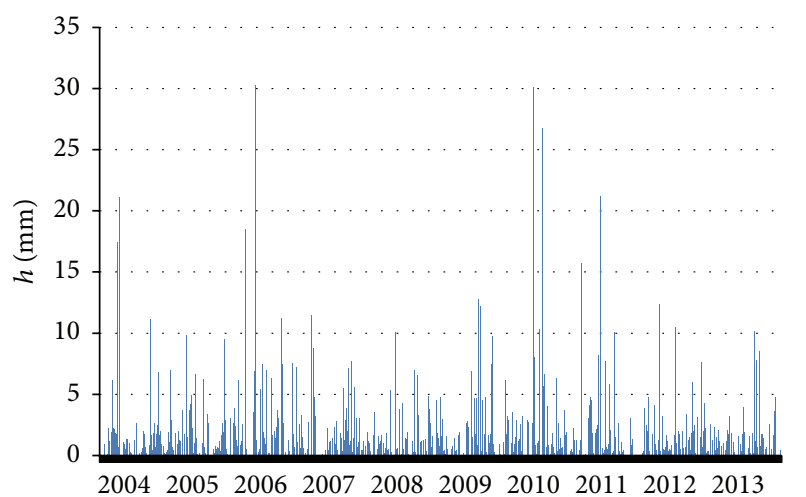

FIGURE 10: Hyetopgraph generated using IRP model for Barletta basin.

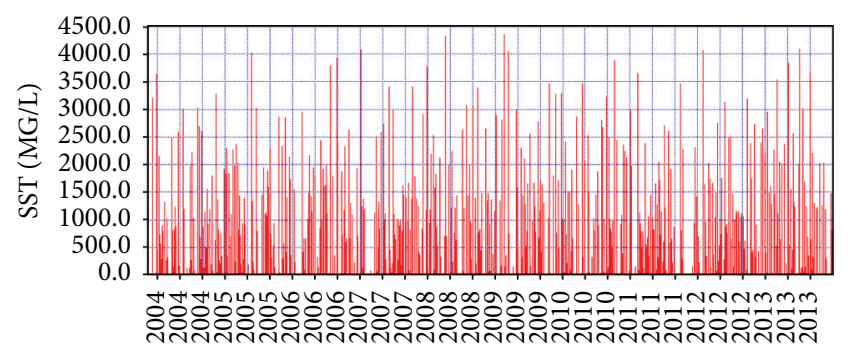

FIGURE 11: Pollutograph generated with SWMM model for Barletta basin.

When the $M(V)$ curve is above the $1: 1$ line, the first flush is noticed and the extent of the phenomenon increases with the slope of the curve for small values of volume.

The $M(V)$ curves obtained from the predicted TSS data of Barletta, Manduria, Cagnano Varano, Presicce, and Ginosa Marina basins are shown in Figure 12. In particular, for each basin the $M(V)$ curve was obtained from the TSS pollutograph simulated starting from the generated synthetic series of precipitation, obtained by selecting a maximum annual rainfall event of duration equal to 15 minutes, with a return period equal to that associated with the design rainfall event (generally equal to 5 years for stormwater network design in Italy).

The $M(V)$ curves in Figure 12 indicate that the first flush phenomenon is occurring in all five catchments. Various hydrologic and sewer system characteristics are usually investigated to determine their influence on the first flush effect [60]. In a combined storm/sanitary sewer system, the first flush load for total suspended solids was shown to correlate well with the event maximum rainfall intensity, storm duration, and antecedent dry weather period [61]. Similar results were also shown in a study involving separate storm and sewer systems [24, 62]. In the current work, from Figure 12, it is worth noting the site dependence of $M(V)$ curves or, in other words, the influence that catchment characteristics have on this phenomenon. In fact, the first flush effect is the most pronounced for the sites that are characterized by high values of impervious surface and slope, and it is much weaker at lower levels of imperviousness and

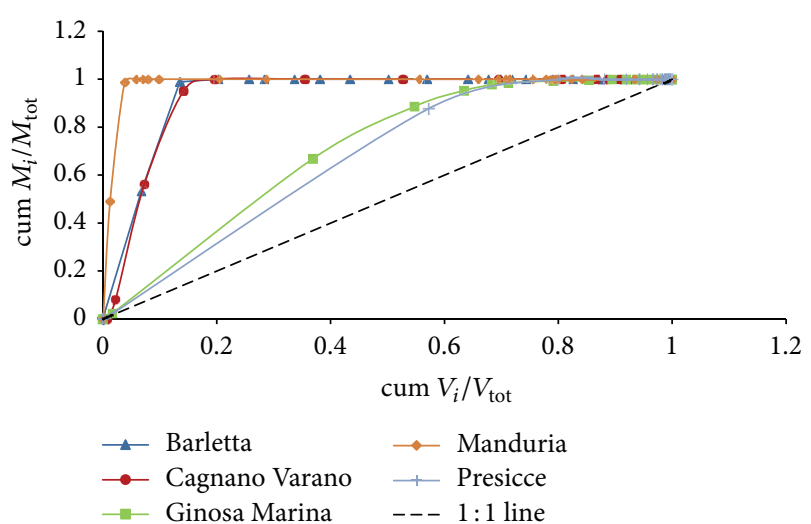

Figure 12: $M(V)$ curves for Barletta, Manduria, Cagnano Varano, Presicce, and Ginosa Marina basins.

TABle 6: Percentage of impervious surface and slope of five catchments.

\begin{tabular}{lcc}
\hline Basins & \% Imp & \% slope \\
\hline Barletta & 93.33 & 0.16 \\
Cagnano Varano & 74.95 & 0.50 \\
Ginosa Marina & 48.98 & 0.09 \\
Manduria & 81.69 & 0.97 \\
Presicce & 30.73 & 0.08 \\
\hline
\end{tabular}

slope too (Table 6). In particular, we can see that the $10 \%$ (for Manduria) and 20\% (for Barletta and Cagnano Varano) of the volume of washed-off water carry the total quantity of TSS from concrete surfaces, while, on the base of the definition of the 30/80 first flush by Bertrand-Krajewski et al. [59], for Ginosa Marina and Presicce, the two cities characterized by the lowest values of slope and percentage of impervious surface, the first $30 \%$ of the volume carries a quantity of TSS, respectively, equal to $50 \%$ and $60 \%$.

\section{Conclusions}

This paper proposes a procedure for evaluating the quality and the quantity characteristics of stormwater runoff in ungauged areas, providing useful information for the design of efficient and sustainable stormwater treatment systems (i.e., first flush capturing devices) and, in general, in the context of the implementation of water treatment procedures for soil pollution management and prevention. In this work a methodology that tries to overcome the lack of runoff quality data in Puglia (Southern Italy), by coupling a rainfall generator model with a storm water management model for evaluating TSS pollutographs, is proposed. The SWMM model uses quantity parameters evaluated using catchments and drainage network characteristics and quality information extracted from observed data obtained by monitoring campaigns.

Five selected ungauged sites, located in the region as the most representative of the evaluated rainfall patterns at regional scale, were used to apply the proposed procedure. In particular, exploiting the IRP rainfall generator model 
proposed by Veneziano and Iacobellis [22], different climatic subareas, characterized by different rainfall features,were identified. By using time series of precipitation generated by the IRP model as input data in the quality model, it was possible to obtain, from the latter, information about qualitative characteristics of runoff in urban catchments, exploiting the data collected during a brief monitoring campaign described in a previous work [24].

Finally, the distribution of pollutant mass versus volume in stormwater discharges, using the so-called " $M(V)$ curves," was provided for the investigated study cases. These curves show that a significant first flush phenomenon is occurring in all five catchments; in particular the first flush effect is the most pronounced for the sites that are characterized by high values of impervious surface and slope, and it is much weaker at lower levels of imperviousness and slope too. Furthermore, a strict correlation between the first flush phenomenon and basin characteristics was found. The characteristics of the $M(V)$ curves depend on the pollutant, the rainfall event, and the overall operation of the sewer system. The possibility of reproducing in a synthetic way the TSS pollutographs in ungauged river basins represents the originality of this paper, with respect to the recent literature in this field. Further improvements may be conducted by new monitoring campaigns focused on the evaluation of the different pollutants present in the water that washes away impervious surfaces. In this way it is possible to improve the performances of the quality models in the context of evaluation and prediction of pollutants for proper and efficient design of sustainable sewer systems in order to prevent soil pollution.

In the next works, the analysis will be extended, in order to assess the relative importance of different parameters and evaluating the role of climate with respect to other features of the sewer system.

\section{Conflict of Interests}

The authors declare that there is no conflict of interests regarding the publication of this paper.

\section{References}

[1] W. R. L. Masamba and D. Mazvimavi, "Impact on water quality of land uses along Thamalakane-Boteti River: an outlet of the okavango $\Delta$, , Physics and Chemistry of the Earth, Parts $A / B / C$, vol. 33, no. 8-13, pp. 687-694, 2008.

[2] C. S. S. Ferreira, A. J. D. Ferreira, R. L. Pato, M. do Carmo Magalhăes, C. de Oliveira Coelho, and C. Santos, "Rainfall-runofferosion relationships study for different land uses, in a suburban area," Zeitschrift für Geomorphologie, vol. 56, no. 3, pp. 5-20, 2012.

[3] C. S. S. Ferreira, R. P. D. Walsh, T. S. Steenhuis et al., "Spatiotemporal variability of hydrologic soil properties and the implications for overland flow and land management in a periurban Mediterranean catchment," Journal of Hydrology, vol. 525, pp. 249-263, 2015.

[4] P. Raska, J. Klimes, and J. Dubisar, "Using local archive sources to reconstruct historical landslide occurrence in selected urban regions of the Czech Republic: examples from regions with different historical development," Land Degradation and Development, vol. 26, no. 2, pp. 142-157, 2015.

[5] J. W. Beniston, R. Lal, and K. L. Mercer, "Assessing and managing soil quality for urban agriculture in a degraded vacant lot soil," Land Degradation \& Development, 2015.

[6] T. K. Udeigwe, J. Young, T. Kandakji, D. C. Weindorf, M. A. Mahmoud, and M. H. Stietiya, "Elemental quantification, chemistry, and source apportionment in golf course facilities in a semi-arid urban landscape using a portable X-ray fluorescence spectrometer," Solid Earth, vol. 6, no. 2, pp. 415-424, 2015.

[7] J. D. Sartor, G. B. Boyd, and F. J. Agardy, "Water pollution aspects of street surface contaminants," Journal of the Water Pollution Control Federation, vol. 46, no. 3, pp. 458-667, 1974.

[8] J. B. Ellis and D. M. Revitt, "Incidence of heavy metals in street surface sediments: solubility and grain size studies," Water, Air, and Soil Pollution, vol. 17, no. 1, pp. 87-100, 1982.

[9] A. Saget, G. Chebbo, and J.-L. Bertrand-Krajewski, "The first flush in sewer systems," Water Science and Technology, vol. 33, no. 9, pp. 101-108, 1996.

[10] J. E. Ball, R. Jenks, and D. Aubourg, "An assessment of the availability of pollutant constituents on road surfaces," Science of the Total Environment, vol. 209, no. 2-3, pp. 243-254, 1998.

[11] J. J. Sansalone, J. M. Koran, J. A. Smithson, and S. G. Buchberger, "Physical characteristics of urban roadway solids transported during rain events," Journal of Environmental Engineering, vol. 124, no. 5, pp. 427-440, 1998.

[12] J. J. Sansalone, F. Calomino, V. Singh, and T. Zheng, "In situ storm water eco-treatment and recharge through infiltration: quality and quantity attenuation," in Proceedings of the 2nd International Conference on New Trend in Water and Environmental Engineering for Safety and Life: Eco-Compatible Solutions for Aquatic Environments, Capri, Italy, June 2002.

[13] J. Vaze and F. H. S. Chiew, "Experimental study of pollutant accumulation on an urban road surface," Urban Water, vol. 4, no. 4, pp. 379-389, 2002.

[14] C. Van Lienden, L. Shan, S. Rao, E. Ranieri, and T. M. Young, "Metals removal from stormwater by commercial and noncommercial granular activated carbons," Water Environment Research, vol. 82, no. 4, pp. 351-356, 2010.

[15] M. Kayhanian, B. D. Fruchtman, J. S. Gulliver, C. Montanaro, E. Ranieri, and S. Wuertz, "Review of highway runoff characteristics: comparative analysis and universal implications," Water Research, vol. 46, no. 20, pp. 6609-6624, 2012.

[16] C. Ciaponi, S. Papiri, and S. Todeschini, "Qualità delle acque meteoriche di dilavamento dei siti sperimentali di Cascina Scala (Pavia) e di Cremona," in Atti dei Seminari "La Tutela Idrica e Ambientale dei Territori Urbanizzati”, Parma e Cosenza, Italy, February 2004 (Italian).

[17] A. Liu, A. Goonetilleke, and P. Egodawatta, "Taxonomy for rainfall events based on pollutant wash-off potential in urban areas," Ecological Engineering, vol. 47, pp. 110-114, 2012.

[18] S. Carroll, A. Liu, L. Dawes, M. Hargreaves, and A. Goonetilleke, "Role of land use and seasonal factors in water quality degradations," Water Resources Management, vol. 27, no. 9, pp. 34333440, 2013.

[19] P. Egodawatta, E. Thomas, and A. Goonetilleke, "Mathematical interpretation of pollutant wash-off from urban road surfaces using simulated rainfall," Water Research, vol. 41, no. 13, pp. 3025-3031, 2007

[20] L.-H. Kim, S.-O. Ko, S. Jeong, and J. Yoon, "Characteristics of washed-off pollutants and dynamic EMCs in parking lots and 
bridges during a storm," Science of the Total Environment, vol. 376, no. 1-3, pp. 178-184, 2007.

[21] N. Alias, A. Liu, P. Egodawatta, and A. Goonetilleke, "Sectional analysis of the pollutant wash-off process based on runoff hydrograph," Journal of Environmental Management, vol. 134, pp. 63-69, 2014.

[22] D. Veneziano and V. Iacobellis, "Multiscaling pulse representation of temporal rainfall," Water Resources Research, vol. 38, no. 8, pp. 131-1313, 2002.

[23] A. Liu, P. Egodawatta, Y. Guan, and A. Goonetilleke, "Influence of rainfall and catchment characteristics on urban stormwater quality," Science of the Total Environment, vol. 444, pp. 255-262, 2013.

[24] M. Di Modugno, A. Gioia, A. Gorgoglione et al., "Build-up/ wash-off monitoring and assessment for sustainable management of first flush in an urban area," Sustainability, vol. 7, pp. 5050-5070, 2015.

[25] V. Iacobellis, P. Claps, and M. Fiorentino, "Climatic control on the variability of flood distribution," Hydrology and Earth System Sciences, vol. 6, no. 2, pp. 229-237, 2002.

[26] M. Fiorentino, S. Manfreda, and V. Iacobellis, "Peak runoff contributing area as hydrological signature of the probability distribution of floods," Advances in Water Resources, vol. 30, no. 10, pp. 2123-2134, 2007.

[27] A. Cerdà and S. H. Doerr, "Soil wettability, runoff and erodibility of major dry-mediterranean land use types on calcareous soils," Hydrological Processes, vol. 21, no. 17, pp. 2325-2336, 2007.

[28] S. D. Keesstra, "Impact of natural reforestation on floodplain sedimentation in the Dragonja basin, SW Slovenia," Earth Surface Processes and Landforms, vol. 32, no. 1, pp. 49-65, 2007.

[29] S. D. Keesstra, L. A. Bruijnzeel, and J. van Huissteden, "Mesoscale catchment sediment budgets: combining field surveys and modeling in the Dragonja catchment, southwest Slovenia," Earth Surface Processes and Landforms, vol. 34, no. 11, pp. 15471561, 2009.

[30] S. D. Keesstra, O. van Dam, G. Verstraeten, and J. van Huissteden, "Changing sediment dynamics due to natural reforestation in the Dragonja catchment, SW Slovenia," CATENA, vol. 78, no. 1, pp. 60-71, 2009.

[31] X. H. Li, J. Yang, C. Y. Zhao, and B. Wang, "Runoff and sediment from orchard terraces in southeastern China," Land Degradation and Development, vol. 25, no. 2, pp. 184-192, 2014.

[32] Z. Liu, Z. Yao, H. Huang, S. Wu, and G. Liu, "Land use and climate changes and their impacts on runoff in the Yarlung Zangbo river basin, China," Land Degradation and Development, vol. 25, no. 3, pp. 203-215, 2014.

[33] L. O. Olang, P. M. Kundu, G. Ouma, and J. Fürst, "Impacts of land cover change scenarios on storm runoff generation: a basis for management of the Nyando Basin, Kenya," Land Degradation and Development, vol. 25, no. 3, pp. 267-277, 2014.

[34] T. Bisantino, R. Bingner, W. Chouaib, F. Gentile, and G. T. Liuzzi, "Estimation of runoff, peak discharge and sediment load at the event scale in a medium-size Mediterranean watershed using the annagnps model," Land Degradation and Development, vol. 26, no. 4, pp. 340-355, 2015.

[35] P. Sarah and M. Zonana, "Livestock redistribute runoff and sediments in semi-arid rangeland areas," Solid Earth, vol. 6, no. 2, pp. 433-443, 2015.

[36] P. Pereira, A. Gimeìnez-Morera, A. Novara et al., "The impact of road and railway embankments on runoff and soil erosion in eastern Spain," Hydrology and Earth System Sciences Discussions, vol. 12, no. 12, pp. 12947-12985, 2015.
[37] W. C. Huber and R. E. Dickinson, Storm Water Management Model, Version 4: User's Manual, Environmental Research Laboratory, Office of Research and Development, US Environmental Protection Agency, Athens, Greece, 1992.

[38] W. James, L. E. Rossman, and W. R. C. James, User's Guide to SWMM5, CHI, Guelph, Canada, 13th edition, 2010.

[39] D. R. Maidment, Handbook of Hydrology, McGraw-Hill, New York, NY, USA, 1993.

[40] R. E. Horton, "An approach toward a physical interpretation of infiltration capacity," Soil Science Society of America, vol. 5, pp. 399-417, 1940.

[41] V. Iacobellis, A. Castorani, A. R. Di Santo, and A. Gioia, "Rationale for flood prediction in karst endorheic areas," Journal of Arid Environments, vol. 112, part A, pp. 98-108, 2015.

[42] W. M. Alley and P. E. Smith, "Estimation of accumulation parameters for urban runoff quality modeling," Water Resources Research, vol. 17, no. 6, pp. 1657-1664, 1981.

[43] T. K. Jewell and D. Adrian, "SWMM stormwater pollutant washoff functions," Journal of the Environmental Engineering Division, vol. 104, no. 5, pp. 1036-1040, 1978.

[44] C. S. Hopkinson Jr. and J. W. Day Jr., "Modeling the relationship between development and storm water and nutrient runoff," Environmental Management, vol. 4, no. 4, pp. 315-324, 1980.

[45] S. Y. Liong, W. T. Chan, and L. H. Lum, "Knowledge-based system for SWMM runoff component calibration," Journal of Water Resources Planning and Management, vol. 117, no. 5, pp. 507-524, 1991.

[46] N. A. Zaghloul and M. A. Abu Kiefa, "Neural network solution of inverse parameters used in the sensitivity-calibration analyses of the SWMM model simulations," Advances in Engineering Software, vol. 32, no. 7, pp. 587-595, 2001.

[47] E. W. Peterson and C. M. Wicks, "Assessing the importance of conduit geometry and physical parameters in karst systems using the Storm Water Management Model (SWMM)," Journal of Hydrology, vol. 329, no. 1-2, pp. 294-305, 2006.

[48] J. Barco, K. M. Wong, and M. K. Stenstrom, "Automatic calibration of the U.S. EPA SWMM model for a large urban catchment," Journal of Hydraulic Engineering, vol. 134, no. 4, pp. 466-474, 2008.

[49] S. B. K. Tan, L. H. C. Chua, E. B. Shuy, E. Y.-M. Lo, and L. M. Lim, "Performances of rainfall-runoff models calibrated over single and continuous storm flow events," Journal of Hydrologic Engineering, vol. 13, no. 7, pp. 597-607, 2008.

[50] ASCE, Design \& Construction of Urban Stormwater Management Systems, ASCE, New York, NY, USA, 1992.

[51] R. H. McCuen, P. Johnson, and R. Ragan, Highway Hydrology: Hydraulic Design Series No. 2; FHWA-SA-96-067, Federal Highway Administration, Washington, DC, USA, 1996.

[52] D. Veneziano, P. Furcolo, and V. Iacobellis, "Multifractality of iterated pulse processes with pulse amplitudes generated by a random cascade," Fractals, vol. 10, no. 2, pp. 209-222, 2002.

[53] V. Iacobellis, G. Gioia, and D. Veneziano, "Rappresentazione delle precipitazioni in Puglia mediante un modello di tipo IRP," in 28. Convegno di Idraulica e Costruzioni Idrauliche, Potenza, Italy, September 2002 (Italian).

[54] V. Iacobellis, G. Gioia, and D. Veneziano, "Estimation of a multifractal model of temporal rainfall using coarse data, Mediterranean storms," in Proceedings of the 3rd EGS Plinius Conference, pp. 293-296, Baja Sardinia, Italy, October 2001. 
[55] I. Portoghese, E. Bruno, N. Guyennon, and V. Iacobellis, "Stochastic bias-correction of daily rainfall scenarios for hydrological applications," Natural Hazards and Earth System Science, vol. 11, no. 9, pp. 2497-2509, 2011.

[56] Regolamento Regionale 9 dicembre 2013, n.26 "Disciplina delle acque meteoriche di dilavamento e di prima pioggia" (attuazione dell'art.113 del D. lgs. n. 152/06 e ss.mm. ed ii.), 2013.

[57] Y. H. Han, S. L. Lau, M. Kayhanian, and M. K. Stensrtom, "Correlation analysis among highway stormwater pollutants and characteristics," in Proceedings of the IWA 8th International Conference on Diffuse/Nonpoint Pollution, Kyoto, Japan, October 2004.

[58] C. Ciaponi, S. Papiri, and S. Todeschini, "Analisi e interpretazione della correlazione tra alcuni parametri inquinanti nella rete fognaria di Cascina Scala in tempo di pioggia," in $X X X$ Convegno di Idraulica e Costruzioni Idrauliche (IDRA '06), Rome, Italy, September 2006.

[59] J.-L. Bertrand-Krajewski, G. Chebbo, and A. Saget, "Distribution of pollutant mass vs volume in stormwater discharges and the first flush phenomenon," Water Research, vol. 32, no. 8, pp. 2341-2356, 1998.

[60] J. M. Hathaway, R. S. Tucker, J. M. Spooner, and W. F. Hunt, "A traditional analysis of the first flush effect for nutrients in stormwater runoff from two small urban catchments," Water, Air, and Soil Pollution, vol. 223, no. 9, pp. 5903-5915, 2012.

[61] K. Gupta and A. J. Saul, "Specific relationships for the first flush load in combined sewer flows," Water Research, vol. 30, no. 5, pp. 1244-1252, 1996.

[62] A. Taebi and R. L. Droste, "First flush pollution load of urban stormwater runoff," Journal of Environmental Engineering and Science, vol. 3, no. 4, pp. 301-309, 2004. 

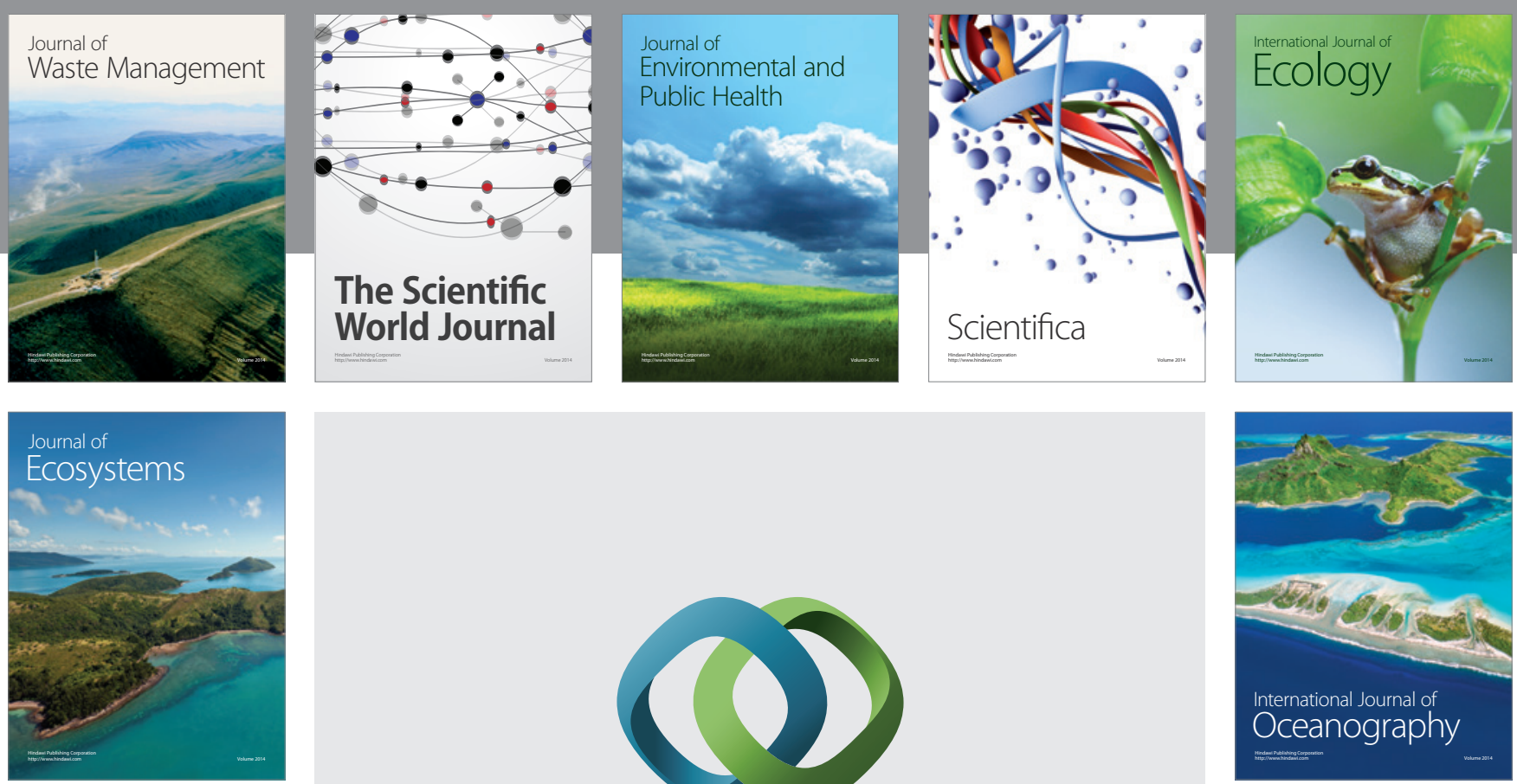

The Scientific World Journal
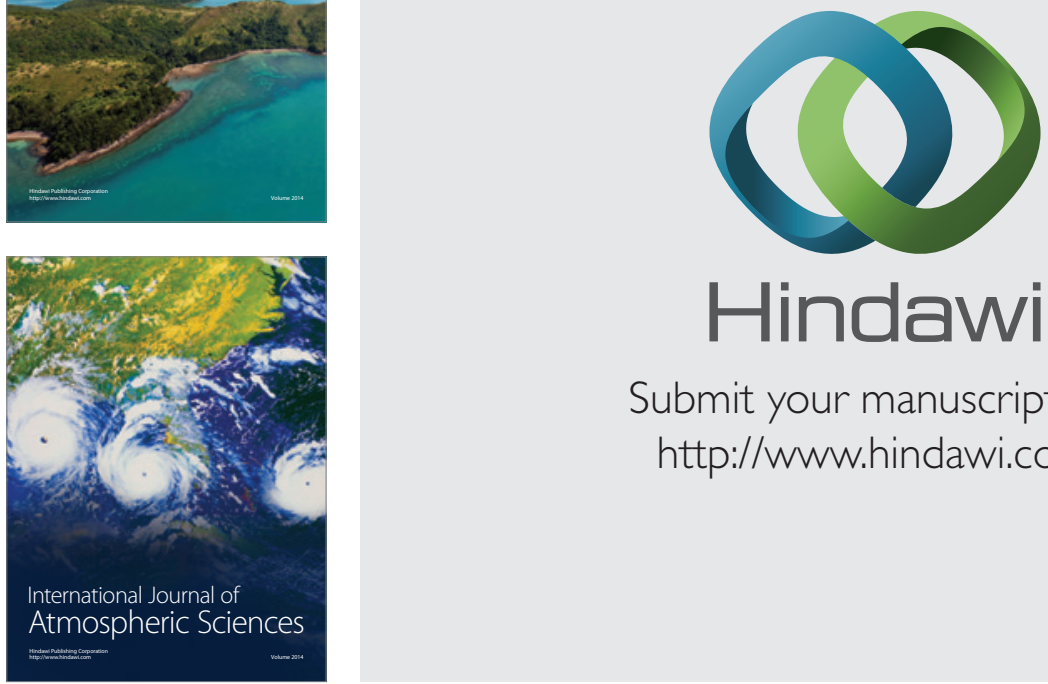

\section{Hindawi}

Submit your manuscripts at

http://www.hindawi.com
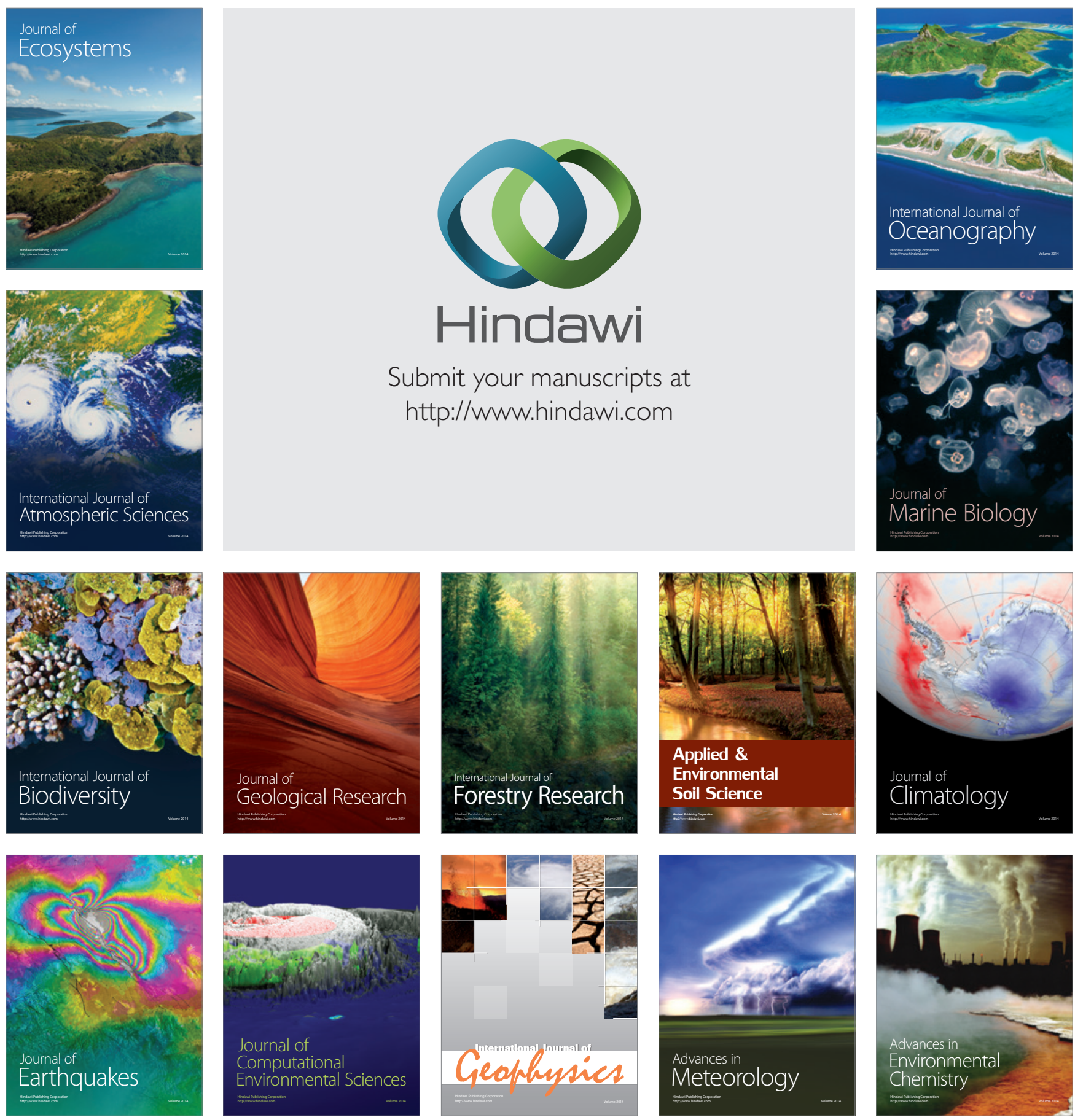